\title{
SEGREGACIÓN ESCOLAR POR NIVEL SOCIOECONÓMICO
}

\section{MIDIENDO EL FENÓMENO Y EXPLORANDO SUS DETERMINANTES *}

\author{
Emmanuel Vazquez ${ }^{* *}$ \\ Tesis de Maestría \\ Maestría en Economía \\ Universidad Nacional de La Plata
}

Directora: Mariana Marchionni

\begin{abstract}
Resumen. Este trabajo hace uso de datos suministrados por el Programa Internacional de Evaluación de Alumnos (PISA) con el objetivo de proveer una cuantificación de los niveles y la evolución de la segregación escolar por nivel socioeconómico en el mundo y contribuir a la discusión de sus determinantes. Los resultados sugieren un ranking de países que muestra a América Latina como una región de alta segregación escolar en términos relativos y donde la segregación entre escuelas públicas y privadas es relevante. Se encuentra además que la segregación escolar por nivel socioeconómico es mayor en aquellos países y períodos de tiempo en los que la desigualdad y la participación del sector privado en la matrícula es mayor, en tanto ciertos patrones de localización geográfica pueden también jugar un rol importante.
\end{abstract}

JEL: D63, I24.

Palabras claves: segregación, educación, PISA.

\footnotetext{
* Este trabajo constituye la tesis de Maestría en Economía de la UNLP, realizada bajo la dirección de Mariana Marchionni. A ella se agradece su valiosa guía y apoyo a lo largo del proceso de investigación. El trabajo se ha beneficiado además de los comentarios y sugerencias de María Laura Alzúa, Leonardo Gasparini, David Jaume y los participantes del seminario de tesis de la Maestría en Economía de la UNLP. Como es usual, los errores remanentes son de exclusiva responsabilidad del autor.

** Centro de Estudios Distributivos, Laborales y Sociales, Facultad de Ciencias Económicas, Universidad Nacional de La Plata - Consejo Nacional de Investigaciones Científicas y Técnicas. E-mail: evazquez@cedlas.org
} 


\section{INDICE}

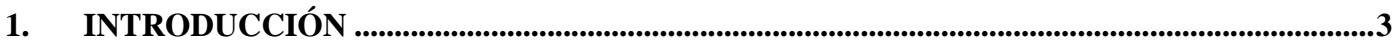

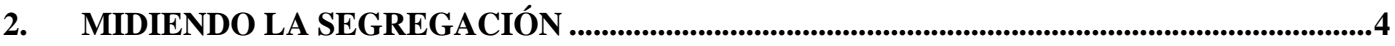

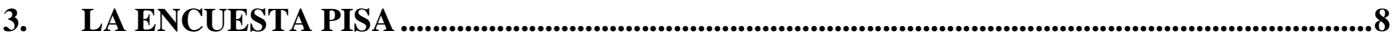

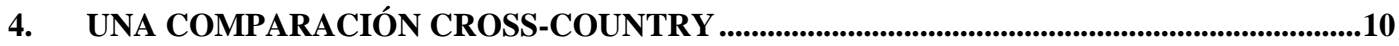

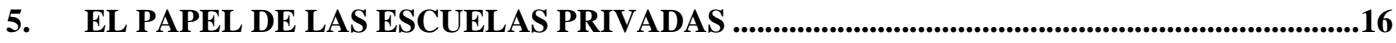

6. EXPLORANDO LOS DETERMINANTES DE LA SEGREGACIÓN ESCOLAR....................20

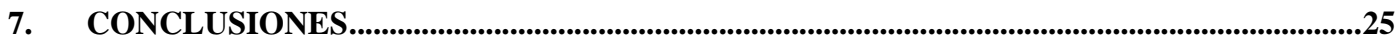

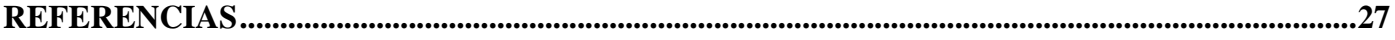

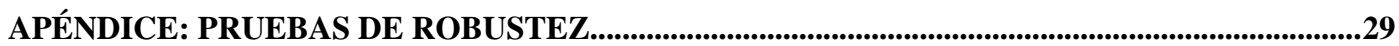




\section{INTRODUCCIÓN}

El fenómeno de segregación ha sido extensamente estudiado en la literatura. Numerosos trabajos han ido dando forma a una definición conceptual y a una manera de medir el fenómeno que aunque aún no ha alcanzado pleno consenso, recientemente ha experimentado un mayor acuerdo. En este contexto, la segregación es entendida como un fenómeno multidimensional que, haciendo a un lado las dimensiones vinculadas al aspecto geográfico, puede definirse como la distribución desigual de grupos con determinado atributo (raza, género, nivel socioeconómico) a lo largo de unidades organizativas (barrios, trabajos, escuelas), con la consecuente pérdida de interacción entre grupos diferentes. La forma más adecuada de cuantificarlo, sin embargo, sigue siendo una cuestión abierta, y aún hoy siguen proponiéndose indicadores para dicha tarea.

A nivel teórico y empírico, el mayor énfasis ha estado en cuantificar y explicar los determinantes de la segregación residencial (véase, por ejemplo, Bénabou (1996) para un análisis teórico y Watson (2009) para un enfoque empírico). Menor atención ha tenido el estudio de la segregación escolar, particularmente por ingreso o nivel socioeconómico, dado que la literatura americana ha otorgado especial interés a la segregación escolar por raza y las fuentes de datos necesarias para un estudio de este tipo fuera de Estados Unidos han sido más limitadas. Recientemente, sin embargo, la disponibilidad de nuevas fuentes de información ha hecho resurgir el interés de algunos en medir la segregación escolar por nivel socioeconómico (véase, por ejemplo, Jenkins, Micklewright y Schnepf (2008)). El presente trabajo se enmarca dentro de esta literatura, pero intenta dar un paso más y avanzar en la explicación de sus determinantes mediante una aproximación empírica.

Numerosas razones fundamentan la necesidad de medir y estudiar este fenómeno. Al empobrecer el rol cohesionador de la escuela como ámbito de integración social, en el que los estudiantes aprenden a convivir con personas de distinta condición económica, social y cultural, la segregación por nivel socioeconómico contribuye a la generación de fenómenos de exclusión y desintegración en la sociedad, dado el papel que juega la escuela en la formación de grupos (Gasparini, Jaume, Serio y Vazquez (2010)). Teorías sociológicas como la desarrollada en la literatura de membresía (Durlauf, 2006) destacan la influencia que tienen los grupos en la determinación de los resultados individuales, ya sea a través de modelos de rol o del efecto de los pares. En ese sentido, los grupos que se forman en las escuelas, cuando son una manifestación de alguna forma de segregación, pueden dar lugar a desigualdades persistentes y trampas de pobreza a través de comportamientos de imitación "negativos". Una mayor segregación de los alumnos de menor nivel socioeconómico en las escuelas estrecha sus posibilidades, contactos y la probabilidad de exposición a códigos, mensajes y conductas necesarias para una movilidad social ascendente (Valenzuela (2008)). Incluso un nivel excesivo de segregación puede amenazar la cohesión social existente (Jenkins et. al. (2008)). Sociólogos como Wilson (1987) sostienen que la falta de exposición de 
los grupos menos favorecidos a los modelos de rol de la clase media y a las redes sociales es una de las causas de la falta de trabajo urbano y la problemática social.

Dada la relevancia del tema, el presente trabajo hace uso de los datos resultantes del Programa Internacional de Evaluación de Alumnos (PISA, por sus siglas en inglés) con el doble objetivo de: i) proveer una cuantificación de los niveles y la evolución de la segregación escolar por nivel socioeconómico en el mundo; ii) contribuir a la discusión de sus determinantes explotando la información que la encuesta PISA es capaz de proporcionar. La disponibilidad de datos a nivel de escuela junto con la posibilidad de efectuar comparaciones entre países hace de esta encuesta una fuente muy rica de información. Cuatro índices de segregación son empleados para medir los niveles de segregación escolar por nivel socioeconómico en los 65 países que participaron del ciclo 2009, en tanto para aquellos países que participaron de la primera edición de PISA se provee una medición de la evolución del fenómeno en la primera década del siglo XXI. Finalmente, se construye un panel de datos con todas las ediciones del programa a los efectos de explorar mediante regresiones multivariadas algunos posibles determinantes de la segregación escolar por nivel socioeconómico.

El resto de este trabajo está ordenado de la siguiente forma. En la sección 2 se resume la literatura sobre medición de la segregación, discutiendo en particular los indicadores que se implementan en este trabajo. La sección 3 describe brevemente la fuente de datos utilizada. En la sección 4 se analizan los niveles de segregación escolar por nivel socioeconómico en más de 60 países para el año 2009 y se muestra la evolución de este fenómeno entre 2000 y 2009. En tanto el apartado 5 discute el rol que juegan las escuelas privadas en la medición de la segregación escolar por nivel socioeconómico, la sección 6 explora sus determinantes desde un punto de vista empírico. Finalmente, la sección 7 concluye con una discusión de los resultados.

\section{MIDIENDO LA SEGREGACIÓN}

La cuantificación de los niveles y la evolución de la segregación escolar por nivel socioeconómico requieren el empleo de algún indicador que resuma en un número el grado en que alumnos de diferente estrato socioeconómico están "separados" entre escuelas. Debido a que la noción de separación puede diferir entre personas, la literatura de medición de la segregación ha desarrollado desde sus inicios una considerable cantidad de índices, bajo la consigna de que la diversidad de la noción de segregación podría hacer insuficiente el empleo de un único indicador. Para mediados del siglo pasado, más de veinte índices habían sido formulados (Jahn, Schmid y Schrag, 1947) y el debate sobre cómo medir un fenómeno que ya mostraba sus varias dimensiones era intenso.

En 1955, el trabajo seminal de Duncan y Duncan sugirió que había poca información en los índices usualmente empleados que no estuviera ya contenida en el denominado Índice de Disimilitud y en la proporción de la población que representa el grupo minoritario (Massey y Denton, 1988). Su artículo representó además una fuerte crítica a 
la operacionalización "naive" del concepto de segregación, constituyendo un llamado a la derivación de índices a partir de conceptualizaciones teóricas sólidas y a la validación de los mismos a partir de un conjunto de criterios suficientemente generales.

Las siguientes dos décadas presenciaron la utilización del Índice de Disimilitud como la medida de segregación estándar, hasta que en 1976 la crítica de Cortese, Falk y Cohen a este indicador tuvo el efecto de reanudar el debate sobre los méritos relativos de los distintos índices. Una gran cantidad de artículos sobre medición de segregación fueron publicados, hasta que finalmente en la década de 1980 los aportes de James y Taeuber (1985) y Massey y Denton (1988) dieron una respuesta al llamado que hicieron Duncan y Duncan treinta años atrás.

James y Taeuber desarrollaron una serie de criterios generales para evaluar las medidas de segregación y eventualmente, validarlas. Basados en el trabajo de Schwartz y Winship (1980) sobre medición de la desigualdad, los autores plantearon una serie de propiedades deseables de un índice de segregación (equivalencia organizacional, invarianza al tamaño, principio de las transferencias e invarianza a la composición). Por su parte, Massey y Denton conceptualizaron la segregación como un fenómeno multidimensional, lo cual permite entender la derivación de un índice en función de la dimensión que intenta medir. Los autores usaron un análisis factorial para clasificar a los índices existentes en cinco dimensiones de segregación: igualdad, exposición, concentración, centralización y agrupamiento. Las tres últimas aluden a nociones de separación vinculadas al aspecto geográfico del fenómeno, no explorado en este estudio. ${ }^{1}$ La dimensión de igualdad, por su parte, está asociada a la distribución desigual de grupos sociales entre unidades organizativas, en tanto la dimensión de exposición se refiere al grado de contacto potencial, o posibilidad de interacción, entre miembros de los grupos dentro de una unidad organizacional.

Massey y Denton sostuvieron la necesidad de medir la segregación con varios índices, que captasen las distintas dimensiones subyacentes del fenómeno. Los criterios inicialmente presentados por James y Taeuber, y posteriormente extendidos para considerar otras características deseables de un índice (Hutchens 2001, 2004), son útiles a los efectos de evaluar la idoneidad de cada indicador. Sin embargo, no siempre el índice con las propiedades más deseables es el que la literatura efectivamente emplea (en particular, el índice que más se utiliza para medir segregación -Disimilitud- no cumple el principio de las transferencias). En este trabajo, se ha optado por la estrategia de presentar una variedad de indicadores de segregación que, si bien en algunos casos se superponen, constituyen una prueba de la robustez de los resultados y ofrecen un panorama completo de las dimensiones del fenómeno que nos interesa cuantificar.

\footnotetext{
${ }^{1}$ La dimensión de concentración se refiere a la cantidad relativa de espacio físico ocupado por grupos minoritarios en el área total. La dimensión de centralización, en tanto, está relacionada al grado en que un grupo está espacialmente localizado cerca del centro del área considerada. Finalmente, la dimensión de agrupamiento está asociada al grado de contigüidad entre las unidades organizativas ocupadas por miembros de los grupos minoritarios.
} 
La aplicación empírica a un estudio de segregación de los índices desarrollados en la literatura requiere dos insumos fundamentales: i) una variable en la que se diferencian los individuos; ii) unidades organizativas a las que se encuentran asignados los mismos. En el caso particular bajo estudio, la variable de diferenciación es el nivel socioeconómico y las unidades organizativas son las escuelas. Los índices tradicionales exigen que el investigador realice una división de los estudiantes en grupos en función de su nivel socioeconómico. Típicamente, la población bajo estudio es dividida en dos grupos, si bien los índices han sido extendidos para considerar casos de múltiples grupos. ${ }^{2}$ Siguiendo a la literatura, se clasificará a los alumnos en estudiantes de nivel socioeconómico relativamente bajo y estudiantes de nivel socioeconómico relativamente alto (en adelante, simplemente bajo y alto), para estudiar su distribución a lo largo de escuelas. El primero de los índices empleados es el de Disimilitud, que se define como:

$$
D=\frac{1}{2} \sum_{i=1}^{k}\left|\frac{x_{1 i}}{X_{1}}-\frac{x_{2 i}}{X_{2}}\right|,
$$

donde $i$ indexa en este caso a las escuelas, $x_{1 i}$ representa el número de alumnos de nivel socioeconómico bajo en la escuela $i, X_{1}$ el total de alumnos de nivel socioeconómico bajo, $x_{2 i}$ el número de estudiantes de nivel socioeconómico alto en el establecimiento escolar $i$ y $X_{2}$ el total de estudiantes de nivel socioeconómico alto. Este índice capta la dimensión de igualdad del fenómeno de segregación y refleja la proporción de estudiantes de nivel socioeconómico bajo que deberían cambiar de escuela para que exista una distribución homogénea de los mismos entre los distintos establecimientos. Sus valores oscilan entre 0 y 1 , donde 0 representa segregación nula y 1 la máxima segregación. ${ }^{3}$

El segundo de los índices utilizados en el presente trabajo capta la dimensión de exposición de la segregación. Se trata del denominado Índice de Aislamiento, definido como:

$$
A=\sum_{i=1}^{k} \frac{x_{1 i}}{X_{1}} \frac{x_{1 i}}{T_{i}}
$$

donde $T_{i}$ es el total de alumnos en la escuela $i$. Este índice puede interpretarse como la probabilidad de que un miembro del grupo de alumnos de nivel socioeconómico bajo se encuentre en un establecimiento escolar con otro miembro de su grupo. Al captar el grado de contacto potencial de los estudiantes de nivel socioeconómico bajo con otros alumnos de su mismo grupo, está afectado por la participación relativa de este grupo en

\footnotetext{
${ }^{2}$ Para una derivación y evaluación detallada de índices multigrupo, véase Reardon y Firebaugh (2002).

${ }^{3}$ Cuando el Índice de Disimilitud arroja valores superiores a 0.6 se dice que se está en presencia de situaciones de hipersegregación (Glaeser y Vidgor, 2001).
} 
la población total de estudiantes. Al igual que $\mathrm{D}$, este índice varía en el rango de $[0,1]$, siendo 1 la segregación máxima posible.

Si bien los indicadores hasta ahora presentados posibilitan captar las dimensiones de igualdad y exposición del fenómeno de segregación escolar (las restantes dimensiones no serán estudiadas, dado que son de particular interés en la cuantificación de la segregación residencial), adicionalmente se hará uso de un índice de creciente aceptación en la literatura: el Índice de la Raíz Cuadrada, propuesto por Hutchens (2001, 2004). A diferencia de los restantes indicadores, este índice es el único que satisface siete propiedades deseables para una buena medida numérica de segregación ${ }^{4}$, entre ellas, descomposición aditiva (la capacidad de descomponer el índice en la suma de la segregación entre agregados de unidades organizacionales -por ejemplo, escuelas públicas y privadas- y al interior de los mismos. Es esta propiedad la que vuelve especialmente interesante el empleo del índice de la Raíz Cuadrada, que se define como:

$$
H=1-\sum_{i=1}^{k} \sqrt{\frac{x_{2 i}}{X_{2}} \frac{x_{1 i}}{X_{1}}}
$$

$\mathrm{y}$, al igual que D, capta la dimensión de igualdad del fenómeno a estudiar. H está definido entre 0 y 1 y puede interpretarse como la suma, a través de las escuelas, del alejamiento de cada escuela de la igualdad distributiva. ${ }^{5}$

La principal desventaja de utilizar indicadores desarrollados en la literatura de segregación por raza para medir segregación por nivel socioeconómico, es que los grupos relevantes deben ser definidos por el investigador y los límites entre estos grupos no son necesariamente obvios (Watson, 2009). En este trabajo se definen dos grupos: alumnos de nivel socioeconómico alto y alumnos de nivel socioeconómico bajo. Una alternativa para solucionar este problema de arbitrariedad es el empleo del Índice de Brecha por Centiles (CGI) propuesto por Watson (2009), que constituye el cuarto indicador de segregación escolar presentado en este estudio. El índice calcula percentiles de alguna variable de bienestar (típicamente ingresos) y evalúa el promedio de las diferencias percentílicas entre los asistentes a cada unidad organizativa y el percentil mediano en cada una de ellas, y se define como:

$$
C G I=\frac{0.25-\frac{1}{N} \sum_{j=1}^{N}\left|p_{j}-p_{\text {medj }}\right|}{0.25},
$$

\footnotetext{
${ }^{4}$ Las siete propiedades son las propuestas por James y Taeuber (1985) - con invarianza al tamaño y a la composición reformuladas como "invarianza a la escala"- más las propiedades de simetría en unidades organizacionales, simetría en grupos, rango y descomposición aditiva.

${ }^{5}$ Para cada escuela, este alejamiento es la diferencia entre la media geométrica de las participaciones de alumnos de distinto nivel socioeconómico en ausencia de segregación y la media geométrica de las participaciones reales (Jenkins et.al. (2008)).
} 
donde $N$ es el total de alumnos, $p_{j}$ es el percentil al que pertenece el estudiante $j$ y $p_{\text {medj }}$ es el percentil al que pertenece el estudiante mediano en la escuela a la que asiste el alumno $j$. Si los estudiantes de distinto nivel socioeconómico estuvieran perfectamente integrados en las escuelas, cada unidad reproduciría la distribución general (percentiles de 0 a 1), la diferencia promedio entre un alumno y la mediana en su unidad sería 0.25 , con lo cual el índice tomaría valor 0 . En el otro extremo, si los estudiantes estuvieran perfectamente segregados, cada unidad contendría en el límite individuos con el mismo nivel socioeconómico y en el mismo percentil, por lo que el índice en este caso toma el valor 1. Al igual que $\mathrm{D}$ y $\mathrm{H}$, este indicador capta la dimensión de igualdad del fenómeno de segregación, pero a diferencia de los primeros, mide un fenómeno potencialmente distinto en tanto no se concentra en dos grupos, sino en toda la distribución de nivel socioeconómico (más precisamente, en cien grupos distintos, correspondientes a cada percentil de la distribución).

El conjunto de índices presentados (Disimilitud, Aislamiento, Raíz Cuadrada y Brecha por Centiles) son utilizados para proveer una caracterización del nivel, la evolución y los determinantes de la segregación escolar. Previo a ello, sin embargo, se discute en la siguiente sección la fuente de datos utilizada.

\section{LA ENCUESTA PISA}

Este trabajo utiliza como fuente de información las bases de datos resultantes del Programa Internacional de Evaluación de Alumnos (PISA, por sus siglas en inglés). Este programa ha sido desarrollado por la OECD con el objetivo de medir las competencias de los estudiantes cercanos al final de su educación obligatoria en las áreas de lengua, matemática y ciencias, y más generalmente evaluar si han adquirido los conocimientos y habilidades necesarios para enfrentar los desafíos que plantea la sociedad actual. Las pruebas PISA se realizan cada 3 años en los países miembros de la OECD y en un grupo de países socios cuyo número ha ido creciendo en el tiempo. Además de los exámenes, el programa recoge información sobre los estudiantes y las escuelas empleando un cuestionario armonizado entre países para los alumnos y directores de las escuelas. En palabras de sus diseñadores, "PISA es el programa internacional más amplio y riguroso que existe para evaluar el rendimiento escolar y reunir datos sobre los factores personales, familiares e institucionales que puedan ayudar a explicar las diferencias de resultados" (OECD, 2010).

La primera encuesta se realizó en el año 2000 y contó con la participación de 43 países. La segunda (2003) se llevó a cabo en 41 países, la tercera (2006) en 57 y la última edición (2009) en $65 .^{6}$ En efecto, además de los países miembros de la OECD, un número cada vez mayor de países de distintas partes del mundo se ha asociado a esta iniciativa, ampliando la cobertura de la encuesta. En el año 2009, 475.460 estudiantes

\footnotetext{
${ }^{6}$ Nueve países adicionales llevaron adelante la misma evaluación en 2010, pero los resultados estarán disponibles en Diciembre de 2011.
} 
completaron la evaluación en un total de 17.145 escuelas, representando alrededor de 22 millones y medio de alumnos. Los esfuerzos realizados en obtener la mayor comparabilidad posible hacen de esta encuesta una valiosa fuente de información para estudiar temas educativos entre países y en el tiempo.

Con el fin de que los resultados obtenidos en los distintos países sean comparables entre sí, y dadas las diferencias en los sistemas educativos existentes, la encuesta PISA no define su población objetivo en términos de cursos educativos, sino en función de su edad. Específicamente, para cada país la encuesta PISA es representativa de los alumnos entre 15 años y 3 meses y 16 años y 2 meses (en adelante, alumnos de 15 años) que han terminado al menos 6 cursos de enseñanza obligatoria. El tipo de muestreo utilizado es estratificado bi-etápico. En la primera etapa, se toma una muestra de todas las escuelas elegibles a nivel nacional (aquellas que tienen alumnos de 15 años), con una probabilidad de selección proporcional al tamaño de cada escuela. Antes del muestreo, las escuelas elegibles son asignadas a grupos mutuamente excluyentes llamados estratos, para mejorar la precisión de las estimaciones. En la segunda etapa, cada escuela seleccionada elabora una lista de sus alumnos de 15 años y se define para cada país un tamaño de cluster objetivo (TCO) -típicamente 35 estudiantes. Cuando la cantidad de alumnos en la lista elaborada por la escuela supera el TCO, se toma una muestra de alumnos del tamaño de cluster objetivo con igual probabilidad de selección para cada uno. En el caso de que la cantidad de alumnos en la lista elaborada por la escuela sea inferior al TCO, se toman todos los estudiantes de 15 años de esa escuela (OECD, 2010).

El diseño de la encuesta PISA permite no sólo evaluar el rendimiento escolar de los alumnos de 15 años, sino también analizar con qué otros estudiantes estos interactúan. En particular, el programa PISA construye una serie de indicadores que posibilitan aproximar el nivel socioeconómico de los estudiantes. El más utilizado para esta tarea es el denominado Índice de status económico, social y cultural (ESCS, por sus siglas en inglés), que será empleado a lo largo de este trabajo como medida de bienestar para estudiar la distribución de alumnos de distinto nivel socioeconómico entre las escuelas. ${ }^{7}$ Este índice es construido a partir del mayor índice de estatus ocupacional del padre o la madre $^{8}$, el mayor grado de educación alcanzado por los padres representado en años de escolarización, y un índice de posesiones familiares que se obtiene preguntando a los

\footnotetext{
${ }^{7} \mathrm{Si}$ bien otros indicadores como la ocupación o educación de los padres podrían utilizarse para aproximar el nivel socioeconómico de los estudiantes, en este trabajo se ha optado por emplear el índice ESCS por cuanto este actúa como medida resumen de estas variables y es el indicador especialmente diseñado por PISA para medir el estatus socioeconómico de los alumnos.

${ }^{8}$ Este índice se obtiene a partir de las respuestas de los alumnos respecto a la ocupación de los padres. Específicamente, recoge los atributos de las ocupaciones que convierten la educación de los padres en ingresos y se deriva a través de una clasificación óptima de los grupos de empleo para maximizar el efecto indirecto de la educación en los ingresos laborales y para minimizar el efecto directo de la educación en los ingresos, sin tener en cuenta la ocupación (OECD, 2010). Para más información acerca de la metodología, véase Ganzeboom, De Graaf y Treiman (1992).
} 
estudiantes si tienen en casa una serie de bienes y servicios. ${ }^{9}$ La elección de estas variables radica en que, normalmente, se entiende que el estatus socioeconómico está determinado por el estatus ocupacional, el nivel de educación y el poder adquisitivo. Las puntuaciones de los estudiantes en el índice ESCS son puntuaciones factoriales que se derivan de un Análisis de los Componentes Principales, el cual se elaboró de modo que la media de la OCDE fuese cero y la desviación típica uno (OECD, 2010). Para los años 2000, 2003 y 2006, se emplea en este estudio el índice ESCS re-estimado y reescalado por OECD para que sea comparable con el del año 2009. ${ }^{10}$

El hecho de que en la encuesta PISA se disponga de datos a nivel de escuela, en lugar de agregados institucionales (como por ejemplo, la escuela pública y la privada), constituye además una ventaja de esta fuente de información en relación a otras fuentes (como por ejemplo las encuestas de hogares). Esto permite estudiar la segregación al interior de los agregados, y brindar una medición más precisa que otros trabajos que estudian el fenómeno por tipo de establecimiento (véase, por ejemplo, Gasparini et. al (2010) para Argentina). En tanto una encuesta de hogares típicamente sólo brinda información sobre el tipo de escuela a la que un alumno asiste (pública, privada subvencionada, privada independiente, etc.), en la encuesta PISA es posible saber con cierta precisión a qué escuela concurre un individuo y cuál es el nivel socioeconómico de los alumnos que asisten a la misma escuela que él.

Dada la posibilidad de estudiar el fenómeno de segregación escolar a nivel de escuelas y de realizar comparaciones entre países, la encuesta PISA constituye una fuente muy rica de información que será empleada en este trabajo para cuantificar el fenómeno de interés y explorar sus determinantes. En la próxima sección se muestran los resultados de utilizar los índices descriptos en la Sección 2 para medir el nivel y la evolución de la segregación escolar por nivel socioeconómico en base a la encuesta PISA.

\section{UNA COMPARACIÓN CROSS-COUNTRY}

Como se mencionó con anterioridad, en este estudio se emplea el Índice de status económico, social y cultural como medida del nivel socioeconómico de los estudiantes. En base a este indicador, es posible agrupar a los alumnos en percentiles y computar el Índice de Brecha por Centiles. El cálculo de los restantes índices requiere, sin embargo, una definición adicional, por cuanto es indispensable determinar previamente qué alumnos serán considerados de nivel socioeconómico bajo y cuáles de nivel

\footnotetext{
${ }^{9}$ La construcción de la escala del índice de posesiones familiares y del ESCS se realizó utilizando la clasificación de Teoría de Respuesta al Ítem (IRT, por sus siglas en inglés). Véase OECD (2010) para una descripción pormenorizada de la construcción de estos índices.

${ }^{10}$ Se agradece a Alla Berezner, Michael Davidson y Maciej Jakubowski, de OECD, por haberme provisto el índice re-escalado oficial.
} 
socioeconómico alto. Los indicadores $\mathrm{D}, \mathrm{A}$ y $\mathrm{H}$ presentados a lo largo del trabajo clasifican a los estudiantes en uno u otro grupo en base a si se encuentran por debajo o por encima del valor mediano del Índice de status económico, social y cultural de su país. Otros valores de corte de esta variable o definición de grupos han sido utilizados para evaluar la robustez de las mediciones, pero estas pruebas de robustez son presentadas en el Apéndice.

Antes de continuar con el análisis es necesario realizar una aclaración respecto a la comparabilidad de los resultados entre países y en el tiempo. Debido a que la encuesta PISA es representativa de la población de 15 años de edad que asiste a la escuela (y ha terminado al menos 6 cursos de enseñanza obligatoria), diferencias en las tasas de escolarización pueden explicar diferencias en los niveles de segregación en tanto las tasas de asistencia a la escuela son generalmente inferiores para los individuos de menor nivel socioeconómico de la población. Es decir, al focalizarse la encuesta en jóvenes de 15 años donde ya pudo haber deserción (diferencial entre grupos socioeconómicos y entre países), existe un potencial problema de sesgo de selección. En un extremo, si en un país las tasas de asistencia a la secundaria son bajas y quienes asisten a la escuela son aquellos de mayor poder adquisitivo puesto que los pobres desertan antes de los 15 años, la segregación puede ser relativamente baja. Esto no representa un inconveniente severo en tanto la interpretación que se haga de los rankings de países y los cambios en el tiempo tenga en cuenta que los niveles de segregación se refieren a los individuos que asisten a la escuela.

Los Gráficos 1.1 a 1.4 muestran los niveles de segregación escolar por nivel socioeconómico de acuerdo a los índices D, A, H y CGI para 65 países en el año 2009. Los rankings son robustos al tipo de índice empleado, oscilando la correlación de rangos de Spearman entre 0.92 y 0.99 . Una primer mirada a los datos muestra que de los cinco países con mayor segregación escolar por nivel socioeconómico, cuatro de ellos pertenecen a América Latina (Perú, Chile, Panamá y México), y los restantes cuatro países de la región que participan del programa PISA (Argentina, Colombia, Uruguay y Brasil) también se hallan en las primeras posiciones. Este hecho coloca a América Latina como una región de relativamente alta segregación escolar en relación a los países de Europa, Asia y América del Norte incluidos en la muestra. ${ }^{11}$

En marcado contraste con los países latinoamericanos, los países nórdicos muestran un panorama muy distinto. En particular, los países escandinavos (Noruega, Finlandia y Suecia), junto con Islandia, muestran niveles de segregación escolar por nivel socioeconómico relativamente bajos. Dinamarca, por su parte, presenta niveles levemente superiores a los de su región, pero en todo caso las diferencias con América Latina son importantes. Por tomar un ejemplo extremo, el índice D muestra que mientras que en Noruega sería necesario trasladar a un 26 por ciento de los alumnos de

${ }^{11}$ El único país de África incluido en la muestra es Túnez, que presenta niveles de segregación escolar por nivel socioeconómico inferiores a los de los países latinoamericanos, a excepción de Brasil según $\mathrm{D}$ y A. 
nivel socioeconómico bajo de escuela para que los estudiantes de nivel socioeconómico alto y bajo se encontraran igualitariamente distribuidos entre las escuelas, en Perú o Chile se necesitaría mudar de establecimiento escolar a un 52 por ciento de los mismos. Este mayor alejamiento de la igualdad distributiva es confirmado por el índice H. De igual forma, el índice A señala que en tanto la probabilidad de que un alumno de nivel socioeconómico bajo se encuentre con otro miembro de su grupo en la escuela a la que asiste asciende a 0.68 en Perú, esta probabilidad de contacto potencial no alcanza a 0.56 en Noruega y Finlandia. Finalmente, las diferencias percentílicas promedio al interior de las escuelas son también mucho más grandes en los países nórdicos que en América Latina, como muestra el CGI.

Gráfico 1.1. Niveles de segregación escolar por nivel socioeconómico. Año 2009. Índice de Disimilitud.

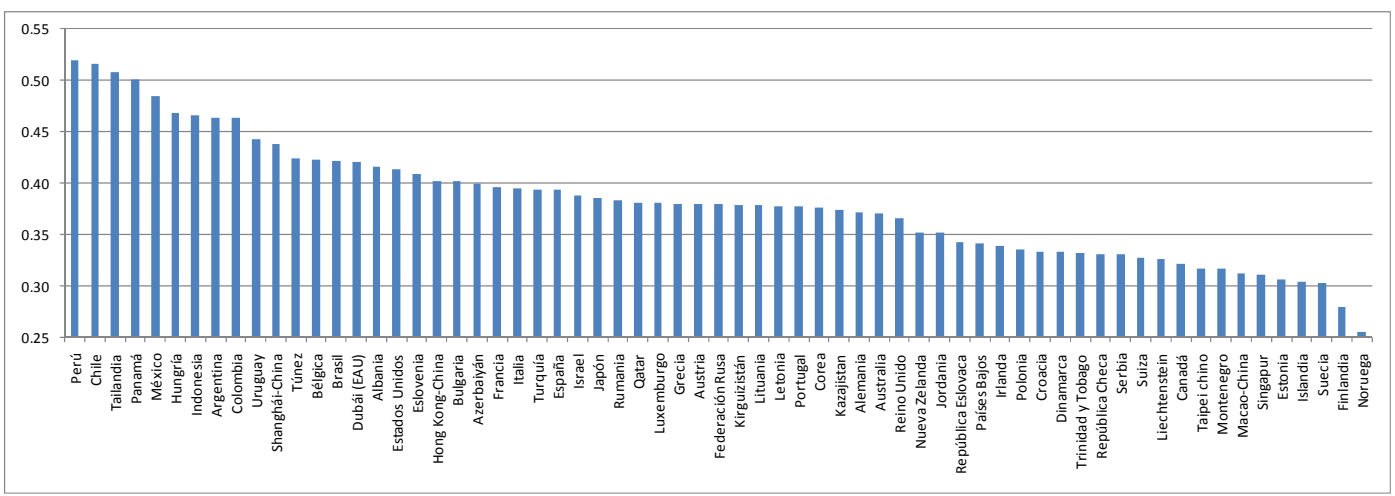

Fuente: Elaboración propia en base a PISA 2009.

Gráfico 1.2. Niveles de segregación escolar por nivel socioeconómico. Año 2009. Índice de Aislamiento.

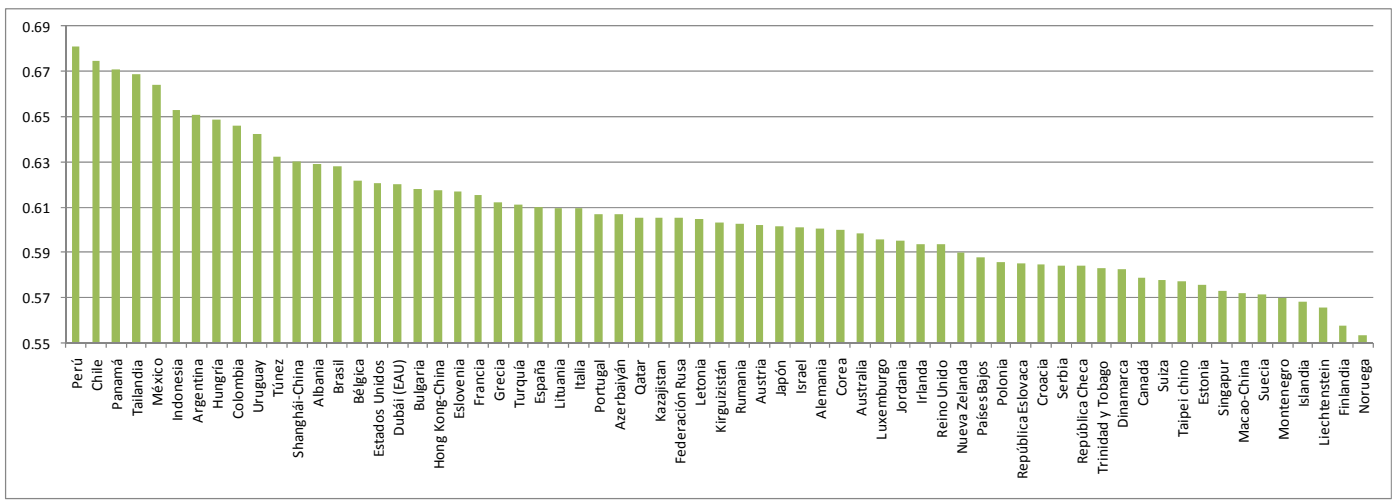

Fuente: Elaboración propia en base a PISA 2009. 
Gráfico 1.3. Niveles de segregación escolar por nivel socioeconómico. Año 2009. Índice de la Raíz Cuadrada.

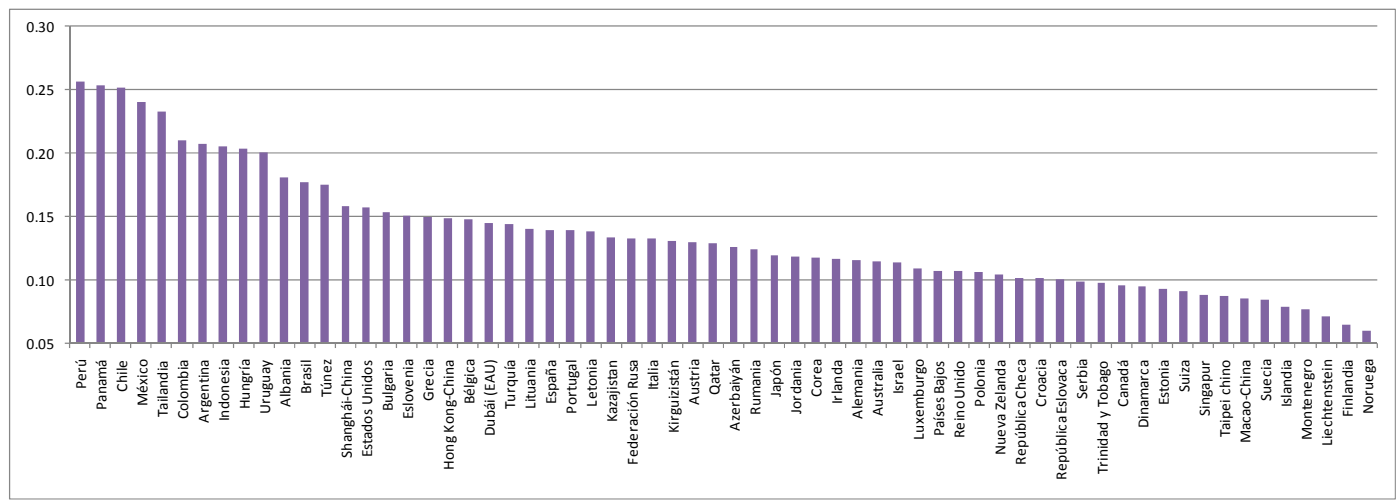

Fuente: Elaboración propia en base a PISA 2009.

Gráfico 1.4. Niveles de segregación escolar por nivel socioeconómico. Año 2009. Índice de Brecha por Centiles (CGI).

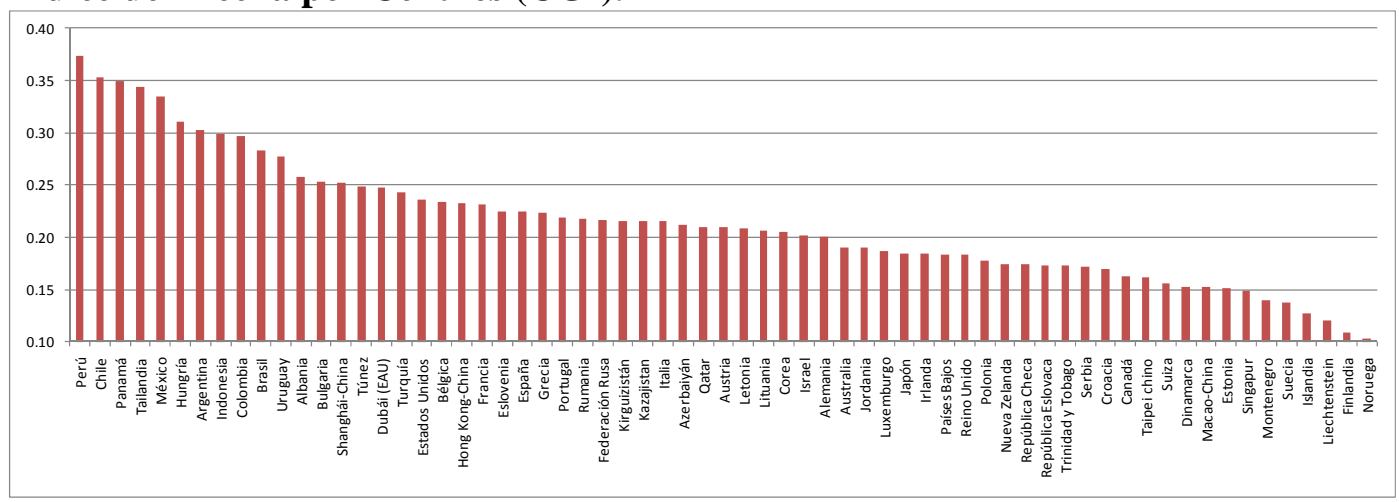

Fuente: Elaboración propia en base a PISA 2009.

La discusión sobre los niveles es valiosa, por cuanto posibilita conocer cuál es la posición relativa de un país en relación al resto, pero tener la posibilidad de medir la evolución de la segregación escolar por nivel socioeconómico y analizar su dinámica es aún mejor. En efecto, saber que un país posee altos niveles relativos de segregación puede inducir a aplicar políticas que ayuden a alivianar el problema, pero es el monitoreo continuo del fenómeno el que permite saber si se está mejor o peor que en el pasado y, con la debida evaluación, averiguar si una política logró los resultados deseados. En ese sentido, aquellos países que realizaron la encuesta PISA en el año 2009 y también en el año 2000 pueden tener una medida de la evolución de este fenómeno en la primera década del siglo XXI. Los resultados de realizar el cómputo de los índices D, A, H y CGI en el año 2000, con la misma metodología del año 2009, y comparar estos valores con los presentados anteriormente para este último año se muestran en los Gráficos 2.1 a 2.4. 
Gráfico 2.1. Cambio en la segregación escolar por nivel socioeconómico entre 2000 y 2009. Índice de Disimilitud.

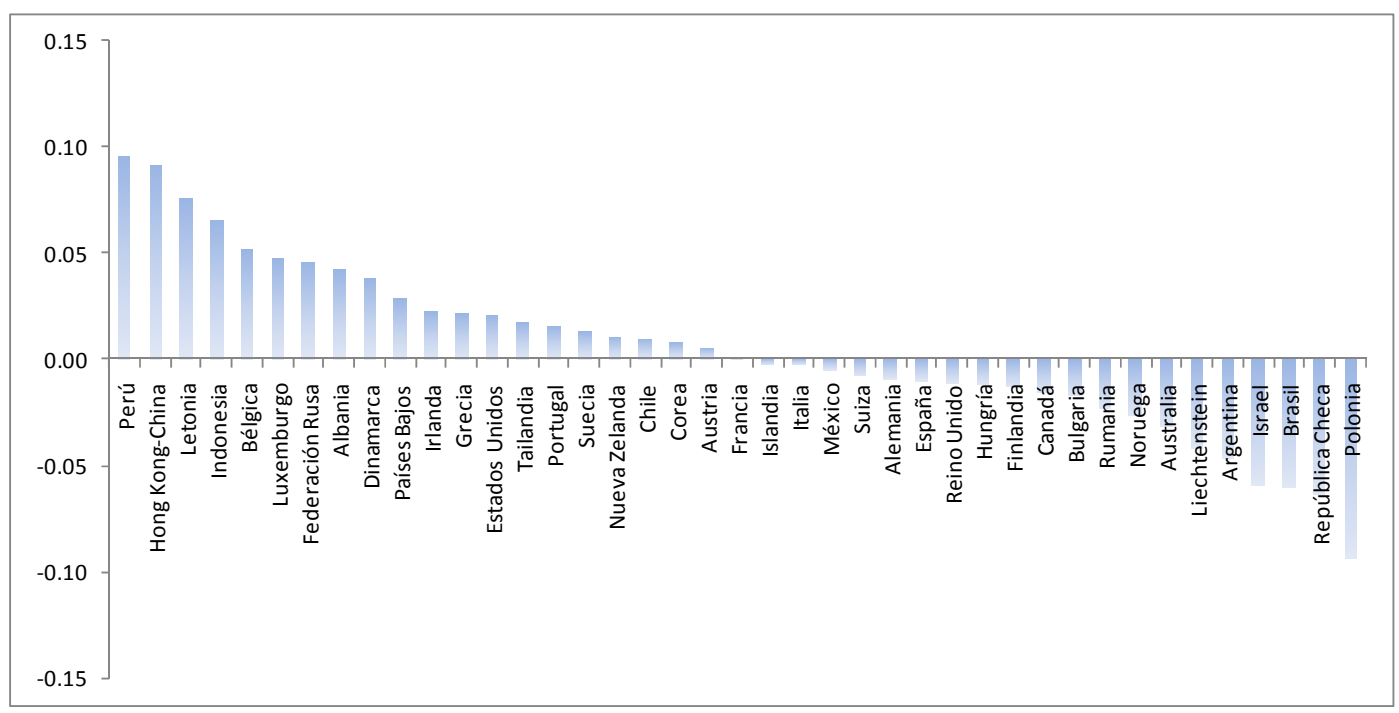

Fuente: Elaboración propia en base a PISA 2000 y 2009.

Gráfico 2.2. Cambio en la segregación escolar por nivel socioeconómico entre 2000 y 2009. Índice de Aislamiento.

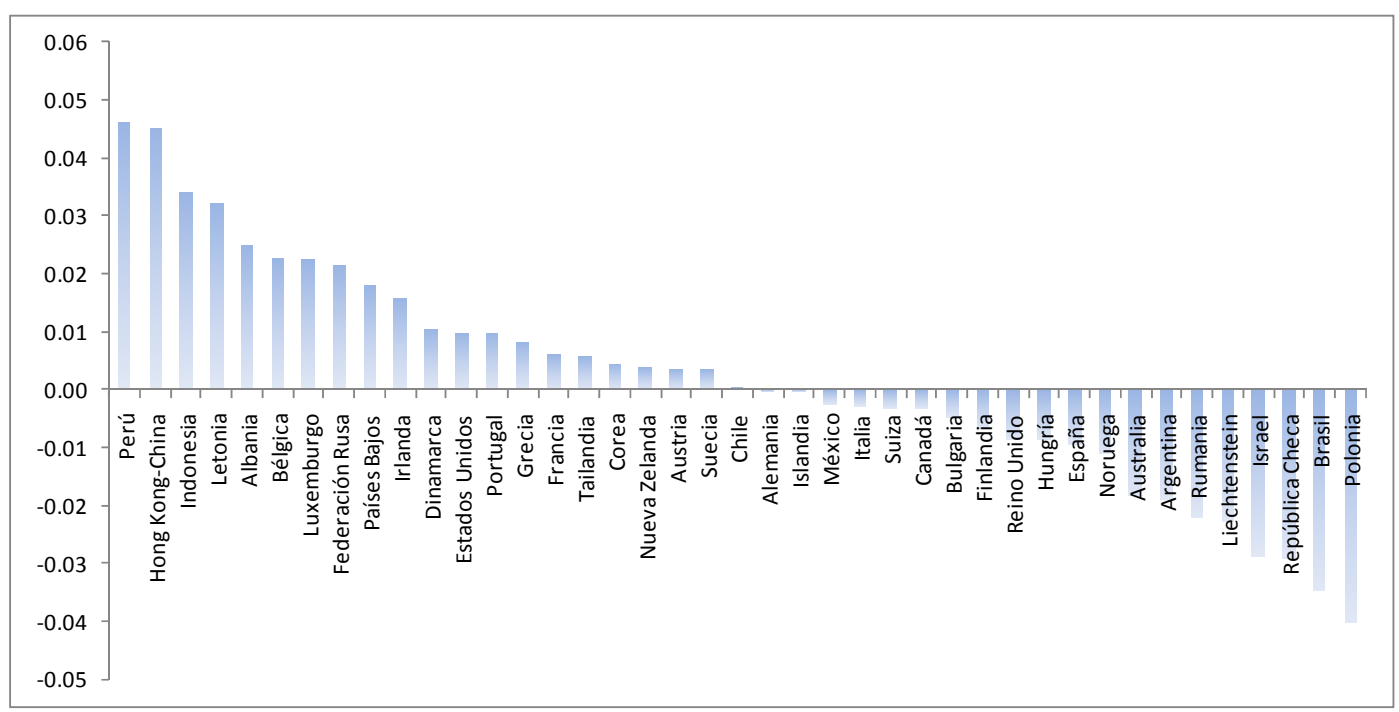

Fuente: Elaboración propia en base a PISA 2000 y 2009. 
Gráfico 2.3. Cambio en la segregación escolar por nivel socioeconómico entre 2000 y 2009. Índice de la Raíz Cuadrada.

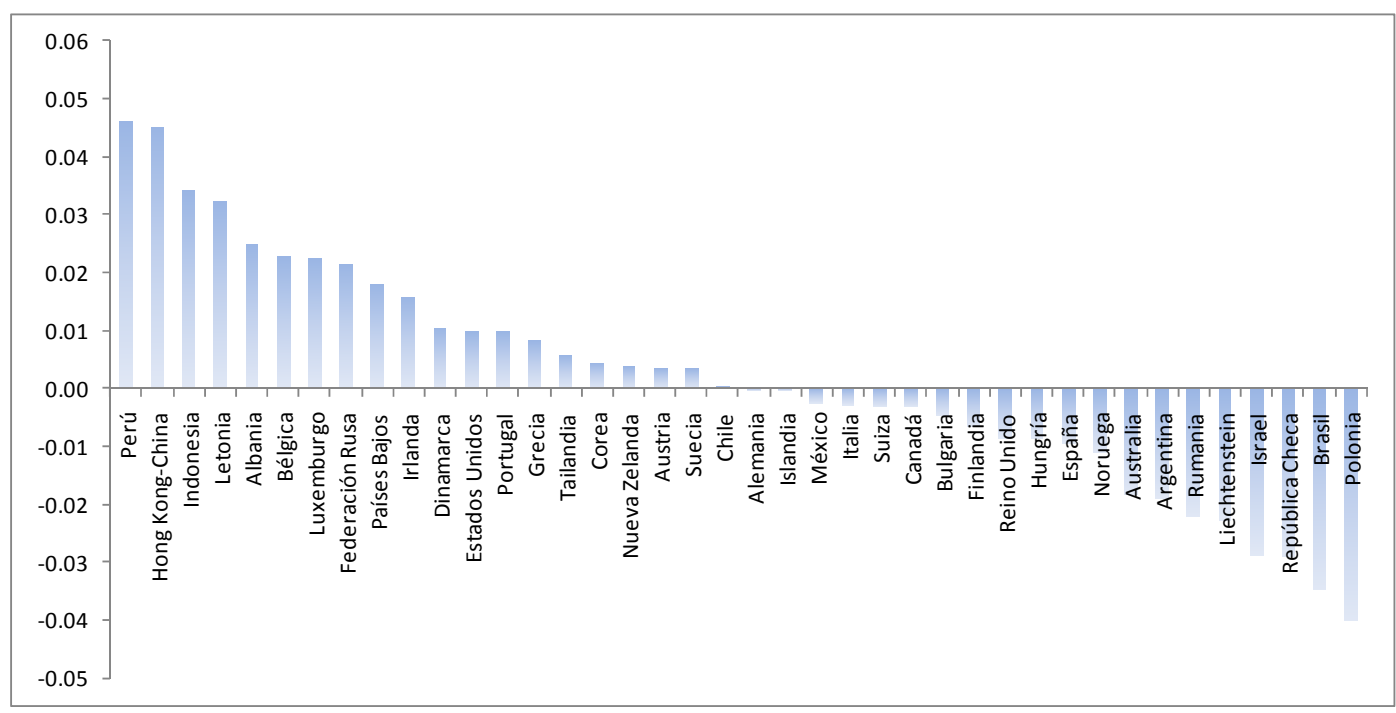

Fuente: Elaboración propia en base a PISA 2000 y 2009.

Gráfico 2.4. Cambio en la segregación escolar por nivel socioeconómico entre 2000 y 2009. Índice de Brecha por Centiles (CGI).

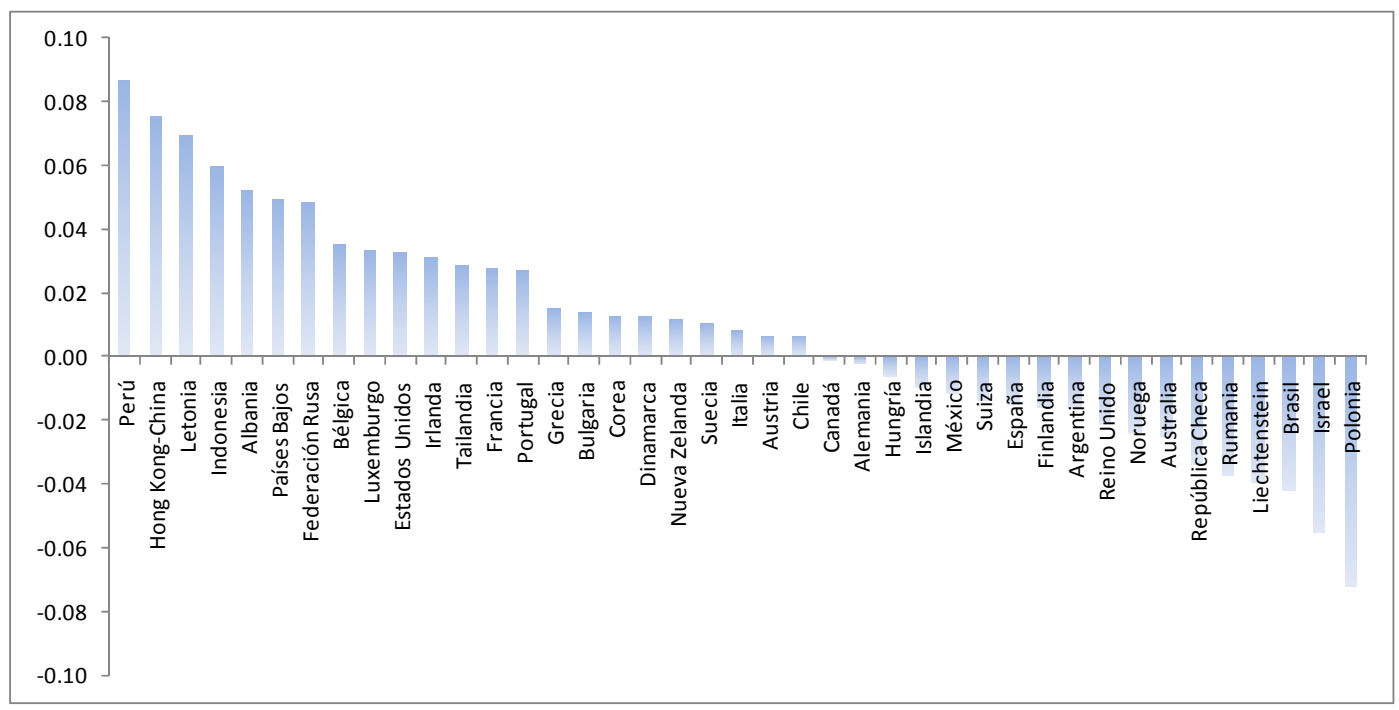

Fuente: Elaboración propia en base a PISA 2000 y 2009.

De los 41 países para los que es posible realizar el cálculo anterior, los países que muestran un mayor aumento absoluto de la segregación escolar por nivel socioeconómico entre 2000 y 2009 son Perú, Hong-Kong, Letonia e Indonesia. Precisamente, dos de estos cuatro países (Perú e Indonesia) se encuentran entre los de mayor segregación en 2009. Albania, que es uno de los países no latinoamericanos ubicados en las primeras posiciones, también ha experimentado un incremento en sus indicadores de segregación. Contrario es el caso de países como Polonia, Brasil, República Checa e Israel, que han mejorado sus indicadores de segregación escolar en 
relación a los de 2009. En Polonia, por ejemplo, las diferencias percentílicas en las escuelas se han ampliado sustancialmente, siendo necesario trasladar de escuelas a un 10 por ciento menos de alumnos de bajo nivel socioeconómico respecto al año 2000 para lograr una distribución igualitaria de los estudiantes de distinto nivel socioeconómico entre los establecimientos educativos.

Presentada la evidencia empírica respecto a la existencia y la evolución del fenómeno de segregación escolar por nivel socioeconómico en los países analizados, se procederá en la siguiente sección a estudiar el papel que juega la presencia de una oferta educativa privada en el nivel de segregación de cada país, siendo éste un paso previo fundamental para una comprensión más acabada de los determinantes del fenómeno.

\section{EL PAPEL DE LAS ESCUELAS PRIVADAS}

En ausencia de una preferencia definida por la segregación, la existencia de una oferta privada de servicios educativos en un país no constituye en sí misma una fuente potencial de segregación por nivel socioeconómico a menos que las escuelas privadas ofrezcan algo que las escuelas públicas no. Si los padres eligen las escuelas para sus hijos basados al menos parcialmente en el producto que puedan obtener éstos de una función de producción educativa que depende en parte de la capacidad y esfuerzo del alumno y en parte de los insumos que la escuela pueda proveer, lo que ofrezcan los establecimientos escolares juega un rol fundamental en la elección de la escuela. En ese sentido, si el sector privado de un país ofrece un servicio diferente del público, por ejemplo en calidad o en términos de una currícula distinta, y el acceso al mismo se encuentra restringido a aquellos que puedan pagar una matrícula, buena parte de los sectores de menor capacidad de pago quedarán excluidos de la educación privada debido al peso de su restricción presupuestaria. Es la existencia de un servicio diferenciado, interactuando con la desigualdad en la capacidad de pago, el que se constituye como fuente de segregación escolar por nivel socioeconómico entre el sector público y el sector privado de un país. Además, la misma capacidad del sector privado de diferenciarse mediante estrategias de segmentación de mercado y concentrarse en diferentes nichos de mercado de distinto poder adquisitivo agrega otra fuente de segregación al interior del sector privado. En presencia de preferencias definidas por la segregación, en donde los padres prefieren establecimientos educativos segregados por sobre aquellos más integrados, o ante la existencia de un motivo "diferenciación" o "estatus" que incentive a los más ricos a segregarse, el sector privado juega un rol importante al permitir que diferencias en capacidades de pago se traduzcan en segregación por la posibilidad de exclusión que una matrícula paga brinda. Por estas razones, un análisis del papel que juegan las escuelas privadas resulta imprescindible antes de adentrarnos en los determinantes más profundos de la segregación escolar por nivel socioeconómico.

Como se mencionó en la Sección 2, el Índice de la Raíz Cuadrada $(\mathrm{H})$ es un indicador que cumple una serie de propiedades deseables entre las que se encuentra la propiedad 
de descomposición aditiva. Es por ello que en esta sección se hará uso de este Índice para medir cuánto de la segregación escolar por nivel socioeconómico es explicado por diferencias entre los sectores público y privado, y cuánto lo explica lo que sucede al interior de los mismos. Siguiendo a Hutchens (2001, 2004), H puede expresarse como la suma de la segregación al interior de los sectores público y privado ( $H$ within) y entre los mismos (H between):

$$
H=H_{\text {within }}+H_{\text {between }}=\omega_{\text {público }} H_{\text {público }}+\omega_{\text {privado }} H_{\text {privado }}+H_{\text {between }}
$$

donde $H_{\text {público }}$ y $H_{\text {privado }}$ son los valores de $\mathrm{H}$ computados usando únicamente los datos de las escuelas de cada sector, y la segregación al interior de los sectores (within) se obtiene como una suma ponderada de $H_{\text {público }}$ y $H_{\text {privado, en la que los ponderadores }}$ reflejan el peso relativo de cada sector $\left(\omega_{\mathrm{i}}=\left\{x_{1 i} / X_{1}\right\}^{0.5}\left\{x_{2 i} / X_{2}\right\}^{0.5}\right.$, siendo $i$ en este caso el tipo de escuela (pública/privada)).

Los resultados de aplicar esta descomposición se muestran en el Cuadro 1. Este Cuadro permite apreciar que la segregación al interior del sector privado es en general superior a la segregación dentro del sector público (en 3 de cada 4 países $H_{\text {privado }}>H_{\text {público }}$ ), lo cual era un resultado esperable dada la mayor capacidad de especialización de este sector. Entre los países de mayor segregación al interior del sector privado se destacan Polonia, México, Kirguizistán e Islandia, con valores del H superiores a 0.4, en tanto hay una serie de países en los que la participación del sector privado y la segregación escolar por nivel socioeconómico dentro del mismo es prácticamente inexistente (Turquía, Rusia y Rumania, por citar tres ejemplos). En lo que respecta a la segregación al interior del sector público, se destacan Tailandia, Hungría e Indonesia como países de alta segregación relativa, y Macao-China, Dubái (EAU) y los países escandinavos como países de baja segregación dentro de las escuelas públicas. La suma ponderada de la segregación al interior de ambos sectores determina que Tailandia y Chile (junto con Indonesia y México) sean los países de mayor segregación escolar within, en tanto los países escandinavos (junto con el Principado de Liechtenstein) ocupen los últimos lugares del ranking.

En el Gráfico 3 puede observarse el ranking de países ordenados de acuerdo al índice $\mathrm{H}$, y la descomposición del mismo en sus componentes within y between. Este índice, al igual que $\mathrm{D}$, mide desigualdad en la proporción de alumnos de nivel socioeconómico bajo y alto que asisten a las distintas escuelas, solo que en lugar de usar diferencias absolutas como D, emplea diferencias proporcionales, lo que da lugar a leves cambios en los ordenamientos. El análisis de la segregación entre las escuelas públicas y privadas arroja algunos resultados interesantes. En particular, los ocho países de América Latina constituyen los ocho países de mayor segregación entre el sector público y el privado de acuerdo al índice H. Salvo algunas otras excepciones, en general la segregación entre ambos sectores no parece ser muy importante. El Gráfico 4 confirma este hecho. Para la mayoría de los países, el porcentaje de la segregación total que puede atribuirse a la desigual distribución de alumnos de distinto nivel socioeconómico entre escuelas públicas y privadas no supera el 10 por ciento. No 
Cuadro 1. Descomposición de la segregación escolar por nivel socioeconómico al interior y entre los sectores público y privado. Índice de la Raíz Cuadrada (H).

\begin{tabular}{|c|c|c|c|c|c|}
\hline \multirow{2}{*}{ País } & \multirow{2}{*}{$\mathrm{H}$} & \multicolumn{4}{|c|}{ Descomposición } \\
\hline & & $\mathrm{H}$ within privado & H within público & $\mathrm{H}$ within & $\mathrm{H}$ between \\
\hline Albania & 0.181 & 0.248 & 0.150 & 0.155 & 0.026 \\
\hline Alemania & 0.116 & 0.129 & 0.114 & 0.114 & 0.002 \\
\hline Argentina & 0.207 & 0.240 & 0.126 & 0.157 & 0.050 \\
\hline Australia & 0.115 & 0.093 & 0.079 & 0.082 & 0.033 \\
\hline Austria & 0.130 & 0.106 & 0.128 & 0.124 & 0.006 \\
\hline Azerbaiyán & 0.126 & 0.305 & 0.124 & 0.125 & 0.002 \\
\hline Brasil & 0.177 & 0.339 & 0.107 & 0.117 & 0.061 \\
\hline Bulgaria & 0.153 & 0.204 & 0.145 & 0.145 & 0.008 \\
\hline Bélgica & 0.148 & 0.159 & 0.098 & 0.140 & 0.008 \\
\hline Canadá & 0.096 & 0.138 & 0.081 & 0.083 & 0.012 \\
\hline Chile & 0.252 & 0.268 & 0.158 & 0.215 & 0.037 \\
\hline Colombia & 0.210 & 0.317 & 0.121 & 0.139 & 0.071 \\
\hline Corea & 0.118 & 0.144 & 0.102 & 0.118 & 0.000 \\
\hline Croacia & 0.101 & 0.157 & 0.091 & 0.090 & 0.011 \\
\hline Dinamarca & 0.095 & 0.059 & 0.101 & 0.091 & 0.004 \\
\hline Dubái (EAU) & 0.145 & 0.134 & 0.064 & 0.116 & 0.029 \\
\hline Eslovenia & 0.150 & 0.176 & 0.147 & 0.147 & 0.004 \\
\hline España & 0.140 & 0.187 & 0.075 & 0.109 & 0.031 \\
\hline Estados Unidos & 0.157 & 0.315 & 0.118 & 0.126 & 0.031 \\
\hline Estonia & 0.093 & 0.193 & 0.088 & 0.091 & 0.002 \\
\hline Federación Rusa & 0.133 & 0.000 & 0.133 & 0.133 & 0.000 \\
\hline Finlandia & 0.065 & 0.084 & 0.063 & 0.064 & 0.000 \\
\hline Grecia & 0.150 & 0.301 & 0.126 & 0.130 & 0.020 \\
\hline Hong Kong-China & 0.148 & 0.148 & 0.148 & 0.148 & 0.000 \\
\hline Hungría & 0.204 & 0.221 & 0.195 & 0.197 & 0.006 \\
\hline Indonesia & 0.205 & 0.225 & 0.188 & 0.204 & 0.002 \\
\hline Irlanda & 0.117 & 0.124 & 0.085 & 0.108 & 0.009 \\
\hline Islandia & 0.079 & 0.423 & 0.075 & 0.077 & 0.003 \\
\hline Israel & 0.114 & 0.128 & 0.110 & 0.113 & 0.001 \\
\hline Italia & 0.133 & 0.287 & 0.123 & 0.132 & 0.001 \\
\hline Japón & 0.120 & 0.134 & 0.103 & 0.111 & 0.008 \\
\hline Jordania & 0.119 & 0.267 & 0.074 & 0.108 & 0.011 \\
\hline Kazajistan & 0.134 & 0.298 & 0.124 & 0.128 & 0.005 \\
\hline Kirguizistán & 0.131 & 0.456 & 0.116 & 0.123 & 0.008 \\
\hline Letonia & 0.138 & 0.321 & 0.136 & 0.138 & 0.000 \\
\hline Liechtenstein & 0.071 & 0.023 & 0.068 & 0.065 & 0.006 \\
\hline Lituania & 0.140 & 0.003 & 0.142 & 0.140 & 0.000 \\
\hline Luxemburgo & 0.109 & 0.182 & 0.096 & 0.108 & 0.001 \\
\hline Macao-China & 0.086 & 0.085 & 0.021 & 0.083 & 0.003 \\
\hline Montenegro & 0.078 & 0.107 & 0.077 & 0.077 & 0.000 \\
\hline México & 0.241 & 0.468 & 0.187 & 0.202 & 0.039 \\
\hline Noruega & 0.060 & 0.026 & 0.060 & 0.060 & 0.000 \\
\hline Nueva Zelanda & 0.104 & 0.053 & 0.089 & 0.086 & 0.019 \\
\hline Panamá & 0.253 & 0.330 & 0.097 & 0.114 & 0.139 \\
\hline Países Bajos & 0.107 & 0.104 & 0.112 & 0.107 & 0.001 \\
\hline Perú & 0.256 & 0.263 & 0.183 & 0.182 & 0.073 \\
\hline Polonia & 0.106 & 0.598 & 0.093 & 0.100 & 0.006 \\
\hline Portugal & 0.139 & 0.270 & 0.113 & 0.135 & 0.005 \\
\hline Qatar & 0.129 & 0.142 & 0.107 & 0.116 & 0.012 \\
\hline Reino Unido & 0.107 & 0.085 & 0.086 & 0.084 & 0.023 \\
\hline República Checa & 0.102 & 0.119 & 0.100 & 0.100 & 0.002 \\
\hline República Eslovaca & 0.101 & 0.097 & 0.100 & 0.099 & 0.001 \\
\hline Rumania & 0.124 & 0.000 & 0.124 & 0.124 & 0.001 \\
\hline Serbia & 0.099 & 0.097 & 0.099 & 0.099 & 0.000 \\
\hline Shanghái-China & 0.159 & 0.274 & 0.142 & 0.155 & 0.004 \\
\hline Singapur & 0.088 & 0.166 & 0.087 & 0.088 & 0.000 \\
\hline Suecia & 0.085 & 0.156 & 0.069 & 0.076 & 0.008 \\
\hline Suiza & 0.092 & 0.140 & 0.085 & 0.088 & 0.004 \\
\hline Tailandia & 0.233 & 0.224 & 0.230 & 0.228 & 0.005 \\
\hline Taipei chino & 0.088 & 0.112 & 0.072 & 0.086 & 0.001 \\
\hline Trinidad y Tobago & 0.098 & 0.116 & 0.094 & 0.096 & 0.002 \\
\hline Turquía & 0.144 & 0.000 & 0.137 & 0.136 & 0.008 \\
\hline Túnez & 0.175 & 0.161 & 0.173 & 0.173 & 0.002 \\
\hline Uruguay & 0.201 & 0.286 & 0.093 & 0.102 & 0.098 \\
\hline
\end{tabular}

Fuente: Elaboración propia en base a PISA 2009. 
Gráfico 3. Descomposición de la segregación escolar por nivel socioeconómico al interior y entre escuelas públicas y privadas. Índice de la Raíz Cuadrada (H).

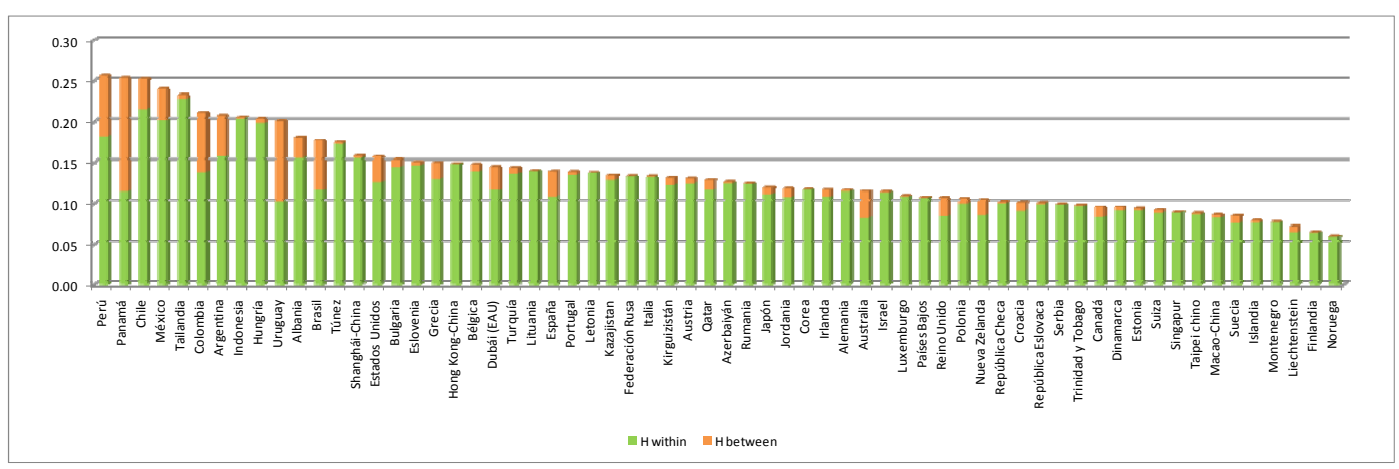

Fuente: Elaboración propia en base a PISA 2009.

Gráfico 4. Porcentaje de segregación escolar explicado por la segregación entre la escuela pública y la privada (H between/H).

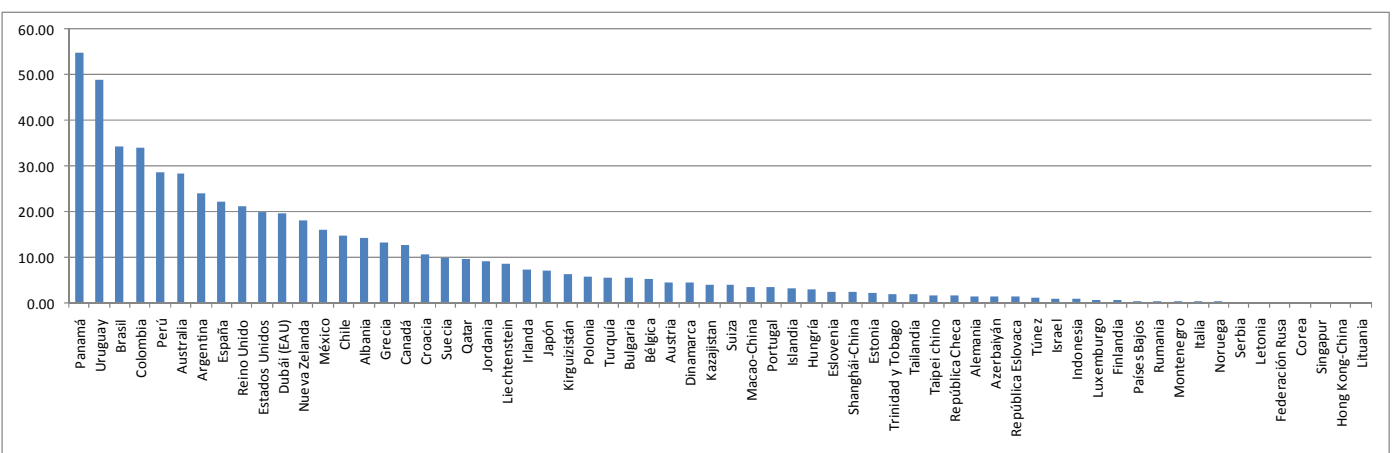

Fuente: Elaboración propia en base a PISA 2009.

obstante, en América Latina (junto con otros países como Australia y España), este fenómeno parece ser más relevante. Por citar los ejemplos más extremos, en Panamá y Uruguay, la segregación entre el agregado de escuelas públicas y privadas explica alrededor del 50 por ciento de la segregación escolar total. La importancia de la distinción entre escuelas privadas y públicas en esos países sugiere que, ya sea porque el sector privado ofrece allí un producto distinto al sector público, o porque la preferencia por la "diferenciación" encuentra en este sector la forma de concretarse, el análisis de la segregación between es importante en esos países. ${ }^{12}$

En resumen, el papel de las escuelas privadas, potencialmente importante en teoría, parece ser más importante por lo que ocurre al interior del sector que por su diferenciación de la escuela pública, salvo en América Latina donde la contribución de la segregación entre sectores a la segregación total es más significativa. Debido a que la

12 El estudio de Gasparini et. al (2010) para Argentina sostiene que la segregación por nivel socioeconómico entre las escuelas públicas y privadas es importante en ese país y ha aumentado entre 2000 y 2009. Los cálculos realizados en este trabajo en base a PISA señalan que para el mismo período, Argentina ha sido uno de los cuatro países en donde la segregación entre escuelas públicas y privadas más ha crecido en términos absolutos (medida por el $\mathrm{H}$ between). 
desigual distribución de alumnos de distinto nivel socioeconómico al interior del sector privado sólo tiene peso en la segregación total cuando la participación de este sector en la matrícula es importante, se deduce que en los países con alta proporción de alumnos en escuelas privadas, la segregación escolar podría ser más alta. Esta hipótesis y otras igualmente interesantes se evaluarán en la próxima sección, en la que se ofrece un análisis empírico de los factores asociados a la segregación escolar por nivel socioeconómico que podrían ser considerados determinantes de este fenómeno.

\section{EXPLORANDO LOS DETERMINANTES DE LA SEGREGACIÓN ESCOLAR}

A pesar del reciente surgimiento de trabajos que proveen mediciones del fenómeno de segregación escolar por nivel socioeconómico, la investigación sobre los factores determinantes del mismo es, por lo menos, escasa. Este estudio intenta llenar parte de ese vacío proveyendo un análisis de los factores asociados a la segregación escolar en base a la información resultante de las encuestas PISA. En particular, resulta de interés preguntarse cuáles son los factores que determinan que los niveles de segregación sean mayores en uno u otro país o momento del tiempo. La respuesta empírica a esta pregunta no es para nada sencilla, por cuanto los efectos causales son difíciles de identificar y la literatura teórica no brinda demasiada orientación respecto a la dirección de los efectos. No obstante, se intenta en esta sección contribuir a la discusión sobre los determinantes de este fenómeno explotando la información que la encuesta PISA puede proveer al respecto.

Los datos de los que se dispone provienen de las encuestas PISA 2000, 2003, 2006 y 2009. Esta fuente de información permite construir un panel de países con los niveles de segregación en cada uno de ellos para cada año y una serie de potenciales variables explicativas. La ventaja de contar con un panel de datos radica fundamentalmente en la

posibilidad de controlar por la heterogeneidad no observada que no varía en el tiempo a través del empleo de efectos fijos por país en regresiones multivariadas. Las especificidades propias de los sistemas educativos de cada país que no cambian en el tiempo pueden ser de esta manera controladas, eliminando los problemas de endogeneidad que pueden surgir por la correlación de éstas con las variables explicativas planteadas. Si bien el empleo de efectos fijos permite reducir parte del problema de endogeneidad, no es suficiente para eliminarlo, por lo que el análisis en las siguientes páginas de las relaciones encontradas se abstrae de hacer cualquier tipo de interpretación causal.

La primera de las potenciales variables explicativas estudiadas es la desigualdad en el nivel socioeconómico de la población estudiantil. En efecto, mucho se ha escrito sobre la relación entre segregación residencial y desigualdad (Sethi y Somanathan (2004), Watson (2009), Reardon y Bischoff (2011)), pero menos clara es la relación de este último fenómeno con la segregación escolar. La intuición descrita en la sección anterior señala que en un país en donde el acceso a determinada educación esté condicionado a 
la posibilidad de pagar una matrícula (ya sea por la existencia de un sector privado o porque el sector público cobra algún cargo por sus servicios), mayor desigualdad en las capacidades de pago se traduce en mayores diferencias en las escuelas a las que alumnos de distinto poder adquisitivo pueden acceder, y eventualmente en mayor segregación escolar. No obstante, aún en presencia de una oferta educativa pública totalmente gratuita, la desigualdad podría jugar un rol importante al influir en el patrón de localización geográfica de las familias. Debido a que algunos padres escogen las escuelas para sus alumnos entre las más cercanas a su domicilio, la desigualdad podría influir indirectamente sobre la segregación escolar a través de su impacto sobre la segregación residencial. Es de esperar una asociación positiva entre ambos tipos de segregación, por lo que de no controlarse por la segregación residencial, el coeficiente asociado a la desigualdad en las regresiones a estimar estará captando tanto la relación directa de la desigualdad y la segregación escolar, como su relación indirecta vía la segregación residencial.

Debido a que la variable de bienestar empleada en este trabajo para aproximar el nivel socioeconómico de los alumnos (el Índice de status económico, social y cultural elaborado por PISA) toma valores negativos y nada garantiza que su valor promedio en cada país sea positivo, no es posible hacer uso de los índices tradicionalmente usados para medir desigualdad (Gini, Theil, etc.), por lo que se utilizará como medida de desigualdad la varianza del Índice de status económico, social y cultural de cada país en cada año. ${ }^{13}$ La media de este índice se incluye también como variable de control en las regresiones realizadas, como medida del nivel socioeconómico promedio de los alumnos de cada país. En efecto, en las secciones anteriores se observaba la ausencia de los países más desarrollados entre los primeros puestos del ranking de segregación escolar, por lo cual resulta interesante indagar si el nivel de vida medio tiene algún impacto sobre este fenómeno. Debido a la imposibilidad de medir la segregación residencial con la encuesta PISA, se incluye además como control demográfico la proporción de estudiantes de cada país que asiste a escuelas ubicadas en zonas rurales (menos de 3000 habitantes), esperando que cuanto mayor sea esta proporción, menor

${ }^{13}$ Es importante destacar que si bien la varianza como indicador de desigualdad no cumple con la propiedad de invarianza a la escala, las posibilidades de aplicar otros indicadores que cumplan las propiedades deseables (principio de las transferencias de Dalton-Pigou, invarianza a la escala e invarianza a las réplicas), tales como el Gini o el coeficiente de variación, se ven severamente reducidas debido a que es imposible o inadecuado computarlos en los casos en los que la media del índice ESCS es negativa (como ocurre para numerosos países y períodos). A los efectos de ofrecer cierta robustez de los resultados al tipo de indicador elegido, se efectuaron las mismas estimaciones empleando el rango intercuartílico como medida de desigualdad en lugar de la varianza, hallándose idénticos resultados a los presentados. Adicionalmente, se probó tomando el Gini de cada país proveniente de los World Development Indicators, confirmándose la asociación positiva entre desigualdad y segregación escolar por nivel socioeconómico encontrada en este trabajo, pero debido a la notable reducción del tamaño de la muestra producto de la falta de datos en estas series se ha preferido conservar la especificación focalizada en la desigualdad de la población estudiantil que se muestra en esta sección. La alternativa de re-escalar el índice ESCS para que sólo tome valores positivos y luego aplicar un indicador de desigualdad estándar como el Gini no ha sido explotada debido a que requiere la suma de un determinado valor al indicador modificando arbitrariamente los niveles de desigualdad según la forma de estandarización elegida, prefiriéndose conservar el índice ESCS tal como es publicado por la OECD. 
sea la segregación escolar por nivel socioeconómico, dado que en estas áreas la cantidad de escuelas es menor y los alumnos de distinto nivel socioeconómico se "mezclan" más fácilmente entre las pocas (o quizás únicas) escuelas existentes.

Dentro del grupo de las variables más relacionadas con el sistema educativo, se incluye como variable explicativa la proporción de alumnos que asiste a una escuela privada, esperando por lo mencionado en la sección anterior que cuanto mayor sea la importancia del sector privado en un país (dado un nivel de desigualdad), mayor sea la segregación escolar por nivel socioeconómico, reflejando en parte el mayor espacio que brinda un sistema educativo con fuerte participación privada para que una preferencia de los alumnos o sus padres por diferenciarse o segregarse se concrete. Debido a los efectos composición existentes en PISA que han sido mencionados en la sección 4, se incluye además la tasa de asistencia al secundario como variable de control. Las tasas brutas de escolarización en el secundario extraídas del Instituto de Estadísticas de la UNESCO constituyen la única variable externa a las bases de datos PISA que se utiliza en las estimaciones, a los efectos de controlar por la posible heterogeneidad de las muestras producto de la deserción temprana en algunos países.

Los cuadros 2.1 a 2.4 muestran los resultados de las regresiones realizadas con efectos fijos por país. En cada uno de ellos, la variable a explicar (la segregación escolar por nivel socioeconómico) se mide mediante un índice distinto (D, A, H o CGI), a los efectos de mostrar que los resultados encontrados son robustos al tipo de indicador empleado para medir la segregación. Las variables explicativas son incorporadas secuencialmente. La primera de las especificaciones -modelo (1)- incorpora como regresor únicamente la desigualdad. Posteriormente, en la segunda $\mathrm{y}$ tercera especificación se agrega el nivel socioeconómico promedio y la proporción de estudiantes en escuelas rurales, respectivamente. Los modelos 4 y 5 incorporan las variables vinculadas a los sistemas educativos que se estima pueden guardar una relación con la segregación escolar por nivel socioeconómico (proporción de alumnos asistentes a escuelas privadas, y la tasa de asistencia bruta al secundario extraída de fuentes de información externas a PISA). Finalmente, en la especificación más completa -modelo (6)- se introducen adicionalmente efectos fijos por año.

Los resultados encontrados sugieren en todos los casos que la segregación escolar por nivel socioeconómico es mayor en aquellos países y momentos del tiempo en los que la desigualdad y la participación del sector privado en la matrícula es mayor. El nivel socioeconómico promedio no resulta ser una variable estadísticamente significativa una vez que se controla por efectos fijos por país. La asociación negativa que se halla en estimaciones preliminares por Pooled OLS desaparece al usar efectos fijos, ${ }^{14}$ lo cual sugiere, en términos de los ordenamientos observados en la Sección 4, que no es el nivel de vida mayor de los países desarrollados el que los mantiene alejados de las primeras posiciones en los rankings de segregación, sino las especificidades propias de estos

\footnotetext{
${ }^{14}$ Idéntico resultado se encuentra si se emplea el PBI per cápita a PPP del 2005 publicado en los World Development Indicators para aproximar el nivel socioeconómico promedio de los países.
} 
países y sus sistemas educativos, las cuales son en buena parte capturadas por los efectos fijos incluidos. El control demográfico incluido (la proporción de alumnos en escuelas rurales) aparece en general asociado negativamente a la segregación, aunque su significatividad desaparece cuándo la segregación es medida por el índice $\mathrm{H}$ y en las especificaciones más sencillas que no emplean efectos fijos por año. Por su parte, la tasa de asistencia al secundario no resulta ser estadísticamente significativa ${ }^{15}$, pero su incorporación como control es relevante dados los posibles efectos composición mencionados con anterioridad.

Cuadro 2.1. Regresiones de segregación escolar por nivel socioeconómico. Variable dependiente: Índice de Disimilitud (D).

\begin{tabular}{|c|c|c|c|c|c|c|}
\hline \multirow{2}{*}{ Variables explicativas } & \multicolumn{6}{|c|}{ Estimaciones por Efectos Fijos } \\
\hline & (1) & $(2)$ & (3) & (4) & (5) & (6) \\
\hline Desigualdad (varianza del ESCS) & $\begin{array}{l}0.116^{* \star *} \\
(0.0200)\end{array}$ & $\begin{array}{l}0.123^{\star * *} \\
(0.0241)\end{array}$ & $\begin{array}{l}0.117^{\star * *} \\
(0.0249)\end{array}$ & $\begin{array}{l}0.105^{\star \star \star} \\
(0.0268)\end{array}$ & $\begin{array}{l}0.113^{\star \star \star} \\
(0.0297)\end{array}$ & $\begin{array}{l}0.121^{\star \star *} \\
(0.0288)\end{array}$ \\
\hline Nivel socioeconómico (ESCS) promedio & & $\begin{array}{c}0.0186 \\
(0.0246)\end{array}$ & $\begin{array}{l}0.00815 \\
(0.0251)\end{array}$ & $\begin{array}{c}0.0114 \\
(0.0252)\end{array}$ & $\begin{array}{c}0.0215 \\
(0.0280)\end{array}$ & $\begin{array}{c}0.0195 \\
(0.0289)\end{array}$ \\
\hline Proporción de estudiantes en escuelas rurales & & & $\begin{array}{l}-0.0883 \\
(0.0531)\end{array}$ & $\begin{array}{l}-0.0853 \\
(0.0542)\end{array}$ & $\begin{array}{l}-0.0976 \\
(0.0588)\end{array}$ & $\begin{array}{l}-0.107^{\star} \\
(0.0559)\end{array}$ \\
\hline Proporción de estudiantes en escuelas privadas & & & & $\begin{array}{c}0.0608^{\star \star *} \\
(0.0154)\end{array}$ & $\begin{array}{c}0.0591^{\star \star *} \\
(0.0158)\end{array}$ & $\begin{array}{c}0.0593^{\star * *} \\
(0.0187)\end{array}$ \\
\hline Tasa de asistencia bruta a la secundaria & & & & & $\begin{array}{l}-0.0151 \\
(0.0186)\end{array}$ & $\begin{array}{l}-0.0223 \\
(0.0222)\end{array}$ \\
\hline Año 2000 & & & & & & $\begin{array}{r}0.00463 \\
(0.00601)\end{array}$ \\
\hline Año 2003 & & & & & & $\begin{array}{l}0.0113^{\star *} \\
(0.00531)\end{array}$ \\
\hline Año 2006 & & & & & & $\begin{array}{c}0.00267 \\
(0.00340)\end{array}$ \\
\hline Constante & $\begin{array}{l}0.275^{\star \star \star} \\
(0.0181)\end{array}$ & $\begin{array}{l}0.272^{\star \star *} \\
(0.0192)\end{array}$ & $\begin{array}{l}0.286^{\star * *} \\
(0.0196)\end{array}$ & $\begin{array}{l}0.286^{\star \star \star} \\
(0.0206)\end{array}$ & $\begin{array}{l}0.298^{\star \star \star} \\
(0.0240)\end{array}$ & $\begin{array}{l}0.294^{\star * *} \\
(0.0266)\end{array}$ \\
\hline Observaciones & 204 & 204 & 195 & 190 & 183 & 183 \\
\hline R cuadrado & 0.218 & 0.222 & 0.216 & 0.223 & 0.246 & 0.281 \\
\hline Número de Países & 66 & 66 & 66 & 66 & 64 & 64 \\
\hline
\end{tabular}

Notas: (a) Errores estándar robustos entre paréntesis. (b) ${ }^{* * *} \mathrm{p}<0.01,{ }^{* *} \mathrm{p}<0.05,{ }^{*} \mathrm{p}<0.1$.

\footnotetext{
${ }^{15}$ Las tasas netas de asistencia al secundario se usaron alternativamente como variable de control, si bien tampoco demostraron ser significativas. Debido a la mayor disponibilidad de datos se ha optado por emplear las tasas brutas en lugar de las netas a los efectos de evitar una pérdida de eficiencia en las estimaciones.
} 
Cuadro 2.2. Regresiones de segregación escolar por nivel socioeconómico. Variable dependiente: Índice de Aislamiento (A).

\begin{tabular}{|c|c|c|c|c|c|c|}
\hline \multirow{2}{*}{ Variables explicativas } & \multicolumn{6}{|c|}{ Estimaciones por Efectos Fijos } \\
\hline & (1) & (2) & (3) & (4) & (5) & (6) \\
\hline Desigualdad (varianza del ESCS) & $\begin{array}{c}0.0561^{\star \star \star} \\
(0.0102)\end{array}$ & $\begin{array}{c}0.0580 * * * \\
(0.0123)\end{array}$ & $\begin{array}{c}0.0543^{\star * *} \\
(0.0128)\end{array}$ & $\begin{array}{c}0.0481^{\star * *} \\
(0.0138)\end{array}$ & $\begin{array}{c}0.0513^{\star \star \star} \\
(0.0148)\end{array}$ & $\begin{array}{c}0.0563^{\star * \star} \\
(0.0139)\end{array}$ \\
\hline Nivel socioeconómico (ESCS) promedio & & $\begin{array}{l}0.00504 \\
(0.0120)\end{array}$ & $\begin{array}{c}-0.000471 \\
(0.0124)\end{array}$ & $\begin{array}{l}0.00187 \\
(0.0123)\end{array}$ & $\begin{array}{l}0.00602 \\
(0.0130)\end{array}$ & $\begin{array}{l}0.00481 \\
(0.0135)\end{array}$ \\
\hline Proporción de estudiantes en escuelas rurales & & & $\begin{array}{l}-0.0419 \\
(0.0264)\end{array}$ & $\begin{array}{l}-0.0405 \\
(0.0268)\end{array}$ & $\begin{array}{l}-0.0448 \\
(0.0303)\end{array}$ & $\begin{array}{l}-0.0506^{*} \\
(0.0281)\end{array}$ \\
\hline Proporción de estudiantes en escuelas privadas & & & & $\begin{array}{l}0.0317^{\star \star *} \\
(0.00806)\end{array}$ & $\begin{array}{l}0.0308^{\star \star \star} \\
(0.00815)\end{array}$ & $\begin{array}{l}0.0312^{\star * \star} \\
(0.00957)\end{array}$ \\
\hline Tasa de asistencia bruta a la secundaria & & & & & $\begin{array}{l}-0.00800 \\
(0.00891)\end{array}$ & $\begin{array}{l}-0.0110 \\
(0.0105)\end{array}$ \\
\hline Año 2000 & & & & & & $\begin{array}{c}0.00275 \\
(0.00278)\end{array}$ \\
\hline Año 2003 & & & & & & $\begin{array}{l}0.00611^{* \star} \\
(0.00259)\end{array}$ \\
\hline Año 2006 & & & & & & $\begin{array}{c}0.00235 \\
(0.00148)\end{array}$ \\
\hline Constante & $\begin{array}{c}0.555^{\star \star \star} \\
(0.00922)\end{array}$ & $\begin{array}{c}0.554^{\star \star \star} \\
(0.00985)\end{array}$ & $\begin{array}{c}0.562^{\star \star *} \\
(0.00999)\end{array}$ & $\begin{array}{l}0.562^{\star \star \star} \\
(0.0104)\end{array}$ & $\begin{array}{l}0.568^{\star \star \star} \\
(0.0127)\end{array}$ & $\begin{array}{l}0.565^{\star * *} \\
(0.0134)\end{array}$ \\
\hline Observaciones & 204 & 204 & 195 & 190 & 183 & 183 \\
\hline R cuadrado & 0.226 & 0.227 & 0.218 & 0.232 & 0.250 & 0.295 \\
\hline Número de Países & 66 & 66 & 66 & 66 & 64 & 64 \\
\hline
\end{tabular}

Notas: (a) Errores estándar robustos entre paréntesis. (b)*** $\mathrm{p}<0.01, * * \mathrm{p}<0.05, * \mathrm{p}<0.1$.

Cuadro 2.3. Regresiones de segregación escolar por nivel socioeconómico. Variable dependiente: Índice de la Raíz Cuadrada (H).

\begin{tabular}{|c|c|c|c|c|c|c|}
\hline \multirow{2}{*}{ Variables explicativas } & \multicolumn{6}{|c|}{ Estimaciones por Efectos Fijos } \\
\hline & (1) & (2) & (3) & (4) & (5) & (6) \\
\hline Desigualdad (varianza del ESCS) & $\begin{array}{l}0.0934^{\star *} \\
(0.0383)\end{array}$ & $\begin{array}{c}0.104^{\star \star} \\
(0.0433)\end{array}$ & $\begin{array}{c}0.109^{\star \star} \\
(0.0476)\end{array}$ & $\begin{array}{c}0.0714^{\star \star *} \\
(0.0218)\end{array}$ & $\begin{array}{c}0.0751^{\star \star *} \\
(0.0231)\end{array}$ & $\begin{array}{c}0.0814^{\star * *} \\
(0.0218)\end{array}$ \\
\hline Nivel socioeconómico (ESCS) promedio & & $\begin{array}{c}0.0266 \\
(0.0369)\end{array}$ & $\begin{array}{c}0.0416 \\
(0.0379)\end{array}$ & $\begin{array}{c}0.000282 \\
(0.0193)\end{array}$ & $\begin{array}{l}0.00434 \\
(0.0209)\end{array}$ & $\begin{array}{l}0.00208 \\
(0.0221)\end{array}$ \\
\hline Proporción de estudiantes en escuelas rurales & & & $\begin{array}{c}-0.0454 \\
(0.0420)\end{array}$ & $\begin{array}{l}-0.0394 \\
(0.0399)\end{array}$ & $\begin{array}{l}-0.0409 \\
(0.0458)\end{array}$ & $\begin{array}{l}-0.0498 \\
(0.0435)\end{array}$ \\
\hline Proporción de estudiantes en escuelas privadas & & & & $\begin{array}{c}0.0452^{\star \star *} \\
(0.0121)\end{array}$ & $\begin{array}{c}0.0440^{\star \star \star *} \\
(0.0123)\end{array}$ & $\begin{array}{c}0.0447^{\star \star *} \\
(0.0138)\end{array}$ \\
\hline Tasa de asistencia bruta a la secundaria & & & & & $\begin{array}{l}-0.0139 \\
(0.0130)\end{array}$ & $\begin{array}{c}-0.0166 \\
(0.0148)\end{array}$ \\
\hline Año 2000 & & & & & & $\begin{array}{c}0.00350 \\
(0.00443)\end{array}$ \\
\hline Año 2003 & & & & & & $\begin{array}{l}0.00791^{\star *} \\
(0.00385)\end{array}$ \\
\hline Año 2006 & & & & & & $\begin{array}{l}0.00422^{*} \\
(0.00245)\end{array}$ \\
\hline Constante & $\begin{array}{c}0.0433 \\
(0.0346)\end{array}$ & $\begin{array}{c}0.0396 \\
(0.0355)\end{array}$ & $\begin{array}{c}0.0452 \\
(0.0401)\end{array}$ & $\begin{array}{c}0.0659 * * * \\
(0.0161)\end{array}$ & $\begin{array}{c}0.0781^{* * *} \\
(0.0194)\end{array}$ & $\begin{array}{c}0.0719^{\star * *} \\
(0.0200)\end{array}$ \\
\hline Observaciones & 204 & 204 & 195 & 190 & 183 & 183 \\
\hline$R$ cuadrado & 0.110 & 0.115 & 0.143 & 0.218 & 0.229 & 0.264 \\
\hline Número de Países & 66 & 66 & 66 & 66 & 64 & 64 \\
\hline
\end{tabular}

Notas: (a) Errores estándar robustos entre paréntesis. (b)*** $\mathrm{p}<0.01,{ }^{* *} \mathrm{p}<0.05,{ }^{*} \mathrm{p}<0.1$. 
Cuadro 2.4. Regresiones de segregación escolar por nivel socioeconómico. Variable dependiente: Índice de Brecha por Centiles (CGI).

\begin{tabular}{|c|c|c|c|c|c|c|}
\hline \multirow{2}{*}{ Variables explicativas } & \multicolumn{6}{|c|}{ Estimaciones por Efectos Fijos } \\
\hline & (1) & (2) & (3) & (4) & (5) & (6) \\
\hline Desigualdad (varianza del ESCS) & $0.116^{\star \star \star}$ & $0.121^{\star * *}$ & $0.117^{\star \star \star}$ & $0.111^{\star \star \star}$ & $0.117^{\star \star \star}$ & $0.123^{\star * \star}$ \\
\hline Nivel socioeconómico (ESCS) promedio & & 0.0122 & 0.00102 & 0.00852 & 0.0144 & 0.00858 \\
\hline & & $(0.0202)$ & $(0.0224)$ & $(0.0227)$ & $(0.0233)$ & $(0.0245)$ \\
\hline Proporción de estudiantes en escuelas rurales & & & $\begin{array}{l}-0.0995^{*} \\
(0.0531)\end{array}$ & $\begin{array}{c}-0.0964^{*} \\
(0.0541)\end{array}$ & $\begin{array}{c}-0.0964 \\
(0.0592)\end{array}$ & $\begin{array}{c}-0.110^{*} \\
(0.0559)\end{array}$ \\
\hline Proporción de estudiantes en escuelas privadas & & & & $0.0489^{* \star \star}$ & $\begin{array}{c}0.0468^{\star * \star} \\
(0.0132)\end{array}$ & $\begin{array}{c}0.0466^{\star * \star} \\
(0.0152)\end{array}$ \\
\hline Tasa de asistencia bruta a la secundaria & & & & & $\begin{array}{l}-0.0213 \\
(0.0175)\end{array}$ & $\begin{array}{l}-0.0247 \\
(0.0177)\end{array}$ \\
\hline Año 2000 & & & & & & $\begin{array}{c}0.00285 \\
(0.00494)\end{array}$ \\
\hline Año 2003 & & & & & & $\begin{array}{c}0.0109^{* *} \\
(0.00505)\end{array}$ \\
\hline Año 2006 & & & & & & $\begin{array}{l}0.00577^{* \star} \\
(0.00283)\end{array}$ \\
\hline Constante & $\begin{array}{l}0.106^{\star \star \star} \\
(0.0153)\end{array}$ & $\begin{array}{l}0.104^{\star \star \star} \\
(0.0160)\end{array}$ & $\begin{array}{l}0.117^{\star \star \star} \\
(0.0173)\end{array}$ & $\begin{array}{l}0.114^{\star \star \star} \\
(0.0182)\end{array}$ & $\begin{array}{l}0.133^{\star \star \star} \\
(0.0236)\end{array}$ & $\begin{array}{l}0.126^{\star \star \star} \\
(0.0218)\end{array}$ \\
\hline Observaciones & 204 & 204 & 195 & 190 & 183 & 183 \\
\hline R cuadrado & 0.275 & 0.277 & 0.290 & 0.306 & 0.316 & 0.360 \\
\hline Número de Países & 66 & 66 & 66 & 66 & 64 & 64 \\
\hline
\end{tabular}

Notas: (a) Errores estándar robustos entre paréntesis. (b) ${ }^{* * *} \mathrm{p}<0.01,{ }^{* *} \mathrm{p}<0.05,{ }^{*} \mathrm{p}<0.1$.

\section{CONCLUSIONES}

Este trabajo contribuyó con evidencia empírica a la medición del fenómeno de segregación escolar por nivel socioeconómico y al análisis de sus determinantes. Para ello, hizo uso de las encuestas PISA, que posibilitan el estudio a nivel de escuelas (en lugar de tipo de establecimiento escolar) y la comparación entre países. Los resultados de computar una serie de índices para 65 países en el año 2009 proveen un ranking de países que muestra a América Latina como una región de alta segregación escolar en términos relativos, y a los países nórdicos como países de baja segregación en relación a sus pares de América, Asia y resto de Europa. La evolución de los indicadores para una serie de países que participaron también en el ciclo correspondiente a PISA 2000 muestra evoluciones dispares, habiendo aumentado la segregación para algunos países y caído para otros, sin existir un patrón general. La descomposición por sector público y privado presentada posteriormente sugiere que la segregación escolar por nivel socioeconómico al interior de las escuelas privadas es en general superior a la que ocurre dentro del agregado de escuelas públicas, pero sólo tiene peso en los casos en los que la participación del sector privado en la provisión de servicios educativos es importante. La segregación entre ambos sectores, por su parte, no alcanza a explicar el 10 por ciento de la segregación total en la mayoría de los países, a excepción de América Latina y otros pocos países en donde la distinción público-privado es relevante para entender la evolución general de la segregación. Finalmente, el análisis de los determinantes de este fenómeno sugiere que la desigualdad, la participación del sector privado y ciertos patrones de localización geográfica son factores que ayudan a entender por qué la segregación escolar es mayor o menor en uno u otro caso, si bien su poder explicativo es limitado y las especificidades de los sistemas educativos de los países 
juegan sin lugar a dudas un rol esencial. Desentrañar con precisión cuáles son estas especificidades constituye el paso lógico siguiente en la investigación. Por el momento, este trabajo constituye un primer paso para ayudar a comprender mejor las causas del fenómeno. Avanzar en el entendimiento de las mismas resulta fundamental a los efectos de evitar que la segregación de los grupos de menor nivel socioeconómico los vuelva más vulnerables, instalando fenómenos de exclusión y desintegración, y difícultando su movilidad social ascendente. 


\section{REFERENCIAS}

Bénabou, Roland (1996). "Equity and efficiency in human capital investment: the local connection." Review of Economic Studies, vol. 63(2), pp. 237-264.

Cortese, Charles F., R. Frank Falk y Jack K. Cohen (1976). "Further Considerations on the Methodological Analysis of Segregation Indices." American Sociological Review, vol. 41, pp. 630-637.

Duncan, Otis D. y Duncan, Beverly (1955). "A Methodological Analysis of Segregation Indexes." American Sociological Review, vol. 20 (2), pp. 210-217.

Durlauf, Steven (2006). "Groups, Social Influences, and Inequality: A Memberships Theory Perspective on Poverty Traps." En Poverty Traps, eds. S. Bowles, S. Durlauf, and K. Hoff. Princeton: Princeton University Press.

Ganzeboom, H.B.G., Paul M. De Graaf y Donald J. Treiman (1992). "A Standard International Socio-economic Index of Occupational Status." Social Science Research, vol. 21(1), pp. 1-56.

Gasparini, Leonardo, David Jaume, Monserrat Serio y Emmanuel Vazquez (2010). "La segregación escolar en Argentina. Reconstruyendo la evidencia." Anales de la Asociación Argentina de Economía Política, Noviembre de 2010.

Glaeser, Edward L. y Jacob L. Vidgor (2001). "Racial Segregation in the 2000 Census: promising news." Center on Urban and Metropolitan Policy. The Brookings InstitutionSurvey Series.

Hutchens, R. (2001). "Numerical measures of segregation: desirable properties and their implications." Mathematical Social Sciences, vol. 42, pp. 13-29.

Hutchens, R. (2004). "One measure of segregation." International Economic Review, vol. 45 , pp. 555-578.

Jahn, Julius A., Calvin F. Schmid y Clarence Schrag (1947). "The Measurement of Ecological Segregation." American Sociological Review, vol. 12, pp. 293-303.

James, David R. y Karl E. Taeuber (1985). "Measures of Segregation." Sociological Methodology, vol. 15, pp. 1-32.

Jenkins, Stephen, John Micklewright y Sylke Schnepf (2008). "Social segregation in secondary schools: how does England compare with other countries?" Oxford Review of Education, vol. 34(1), pp. 21-38.

Massey, Douglas S. y Nancy A. Denton (1988). "The Dimensions of Racial Segregation." Social Forces, vol. 67(2), pp. 281-315.

OECD (2010). PISA 2009 Results: What Students Know and Can Do - Student Performance in Reading, Mathematics and Science.

Reardon, Sean y Kendra Bischoff (en impresión). "Income inequality and income segregation." American Journal of Sociology. 
Reardon, Sean y Glenn Firebaugh (2002). "Measures of Multigroup Segregation." Sociological Methodology, vol. 32, pp. 33-67.

Schwartz, Joseph y Christopher Winship (1980). "The Welfare Approach to Measuring Inequality." Sociological Methodology, vol. 9, pp. 1-36.

Sethi, Rajiv y Rohini Somanathan (2004). "Inequality and segregation." The Journal of Political Economy, vol. 112(6), pp. 1296-1321.

Valenzuela Juan P. (2008). "Evolución de la Segregación Socioeconómica de los Estudiantes Chilenos y su Relación con el Financiamiento Compartido." Proyecto FONIDE, No. 211 - 2006. Ministerio de educación de Chile, Universidad de Chile.

Watson, Tara (2009). "Inequality and the measurement of residential segregation by income in American neighborhoods." Review of Income and Wealth, vol. 55(3), pp. 820-844.

Wilson, William (1987). The Truly Disadvantaged: The Inner City, the Underclass, and Public Policy. Chicago: University of Chicago Press. 


\section{APÉNDICE: PRUEBAS DE ROBUSTEZ}

En este apéndice se muestran algunas de las pruebas de robustez realizadas a lo largo del presente estudio. En particular, resulta especialmente relevante señalar cuán sensibles son los niveles y la evolución de la segregación escolar por nivel socioeconómico que sugieren los índices $\mathrm{D}, \mathrm{A}$ y $\mathrm{H}$ a la definición de grupos que se adopte, así como las estimaciones realizadas a los efectos de explorar los determinantes de este fenómeno. En el cuerpo principal del trabajo se consideró alumnos de nivel socioeconómico relativamente bajo a aquellos estudiantes cuyo Índice de status económico, social y cultural (ESCS) se encontraba por debajo del valor mediano del índice para su país. En este apéndice se muestran los resultados que surgen de cambiar la definición de grupos de dos maneras distintas: i) definiendo al grupo de nivel socioeconómico relativamente bajo como aquellos alumnos que pertenecen al primer quintil del índice ESCS de su país; ii) definiendo al grupo de nivel socioeconómico relativamente bajo como aquellos estudiantes que pertenecen a los cuatro primeros quintiles del índice ESCS de su país.

Los niveles de segregación escolar por nivel socioeconómico para el año 2009 de acuerdo a estas dos definiciones alternativas se muestran en los gráficos A1.1 a A1.3 y A2.1 a A2.3. En términos generales, se observa que los países nórdicos siguen destacándose como países de baja segregación relativa, en tanto América Latina sigue posicionándose como una región de alta segregación relativa, si bien ocurren algunos cambios en los ordenamientos por demás interesantes. En relación a la evolución de la segregación escolar por nivel socioeconómico, el conjunto de gráficos A3 y A4 son útiles por cuanto posibilitan observar si los cambios que se muestran en el cuerpo principal del trabajo obedecen en mayor medida a una distribución más desigual del quintil más pobre respecto al resto que al alejamiento del quintil más rico de los cuatro primeros quintiles. Por ejemplo, el análisis de los índices para Perú sugiere que el incremento notable de la segregación que se indicó en el cuerpo principal del trabajo es resultado de un fuerte alejamiento del quintil más pobre respecto al resto, y que si bien la segregación del quintil más rico ha aumentado, su importancia cuantitativa ha sido menor.

Finalmente, el conjunto de cuadros A1 y A2 confirman los resultados hallados de que la desigualdad se encuentra positivamente relacionada con la segregación escolar por nivel socioeconómico y otorgan en general más fuerza a la hipótesis de que la proporción de estudiantes en escuelas rurales está negativamente relacionada con esta última. Salvo alguna excepción, el nivel socioeconómico promedio del país y las tasas de asistencia al secundario siguen siendo estadísticamente no significativas. Por último, los resultados de este apéndice y de otras especificaciones revelan una relación positiva entre la participación del sector privado y la segregación del quintil más rico de ESCS, aunque no se encuentra un efecto significativo respecto a la del quintil más pobre. 
Gráfico A1.1. Niveles de segregación escolar por nivel socioeconómico. Año 2009. Índice de Disimilitud (nivel socioeconómico bajo: 1er quintil de ESCS).

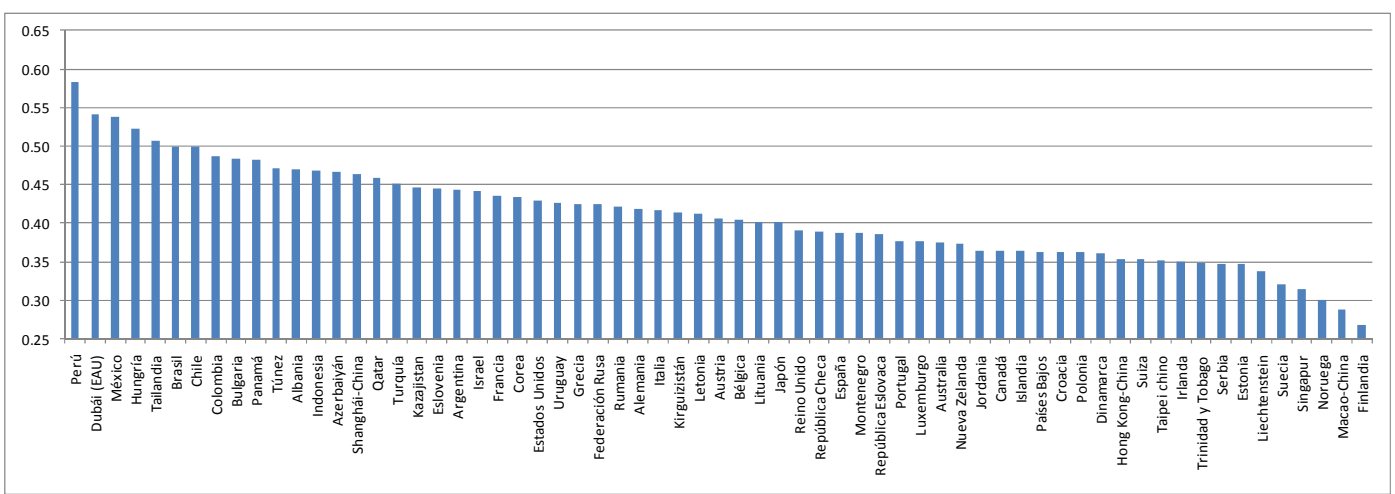

Fuente: Elaboración propia en base a PISA 2009.

Gráfico A1.2. Niveles de segregación escolar por nivel socioeconómico. Año 2009. Índice de Aislamiento (nivel socioeconómico bajo: 1er quintil de ESCS).

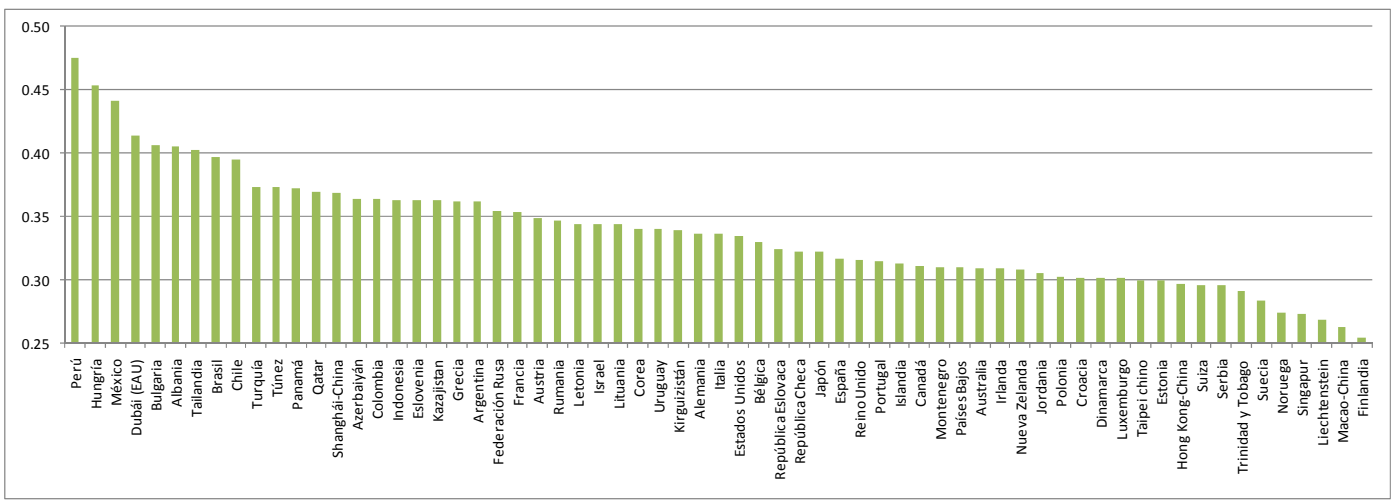

Fuente: Elaboración propia en base a PISA 2009.

Gráfico A1.3. Niveles de segregación escolar por nivel socioeconómico. Año 2009. Índice de la Raíz Cuadrada (nivel socioeconómico bajo: 1er quintil de ESCS).

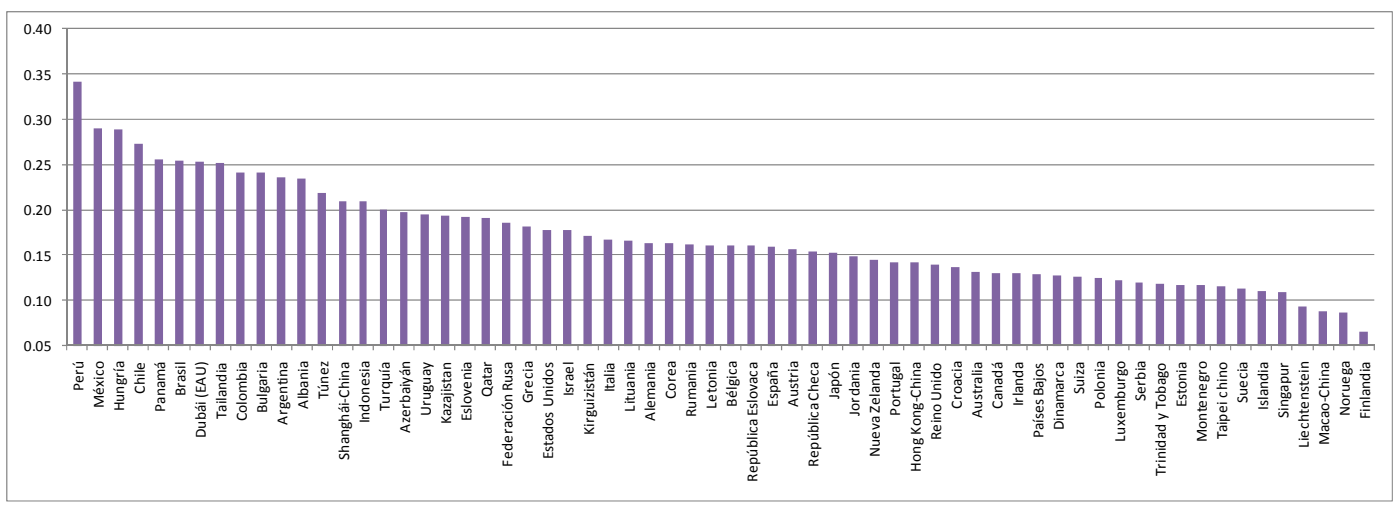

Fuente: Elaboración propia en base a PISA 2009. 
Gráfico A2.1. Niveles de segregación escolar por nivel socioeconómico. Año 2009. Índice de Disimilitud (nivel socioeconómico bajo: 4 quintiles más bajos de ESCS).

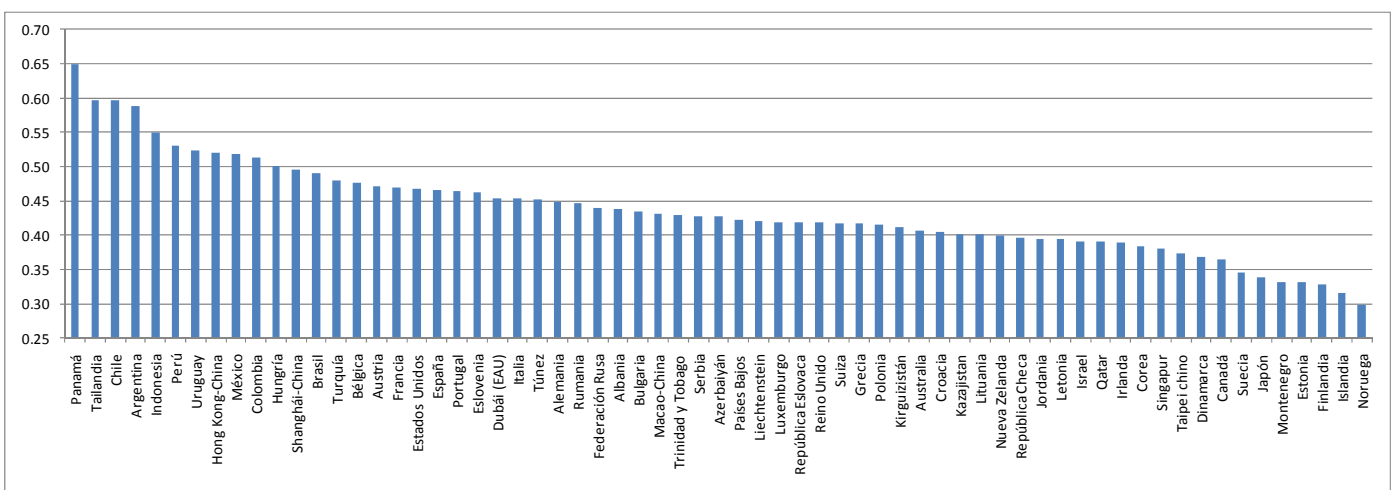

Fuente: Elaboración propia en base a PISA 2009.

Gráfico A2.2. Niveles de segregación escolar por nivel socioeconómico. Año 2009. Índice de Aislamiento (nivel socioeconómico bajo: 4 quintiles más bajos de ESCS).

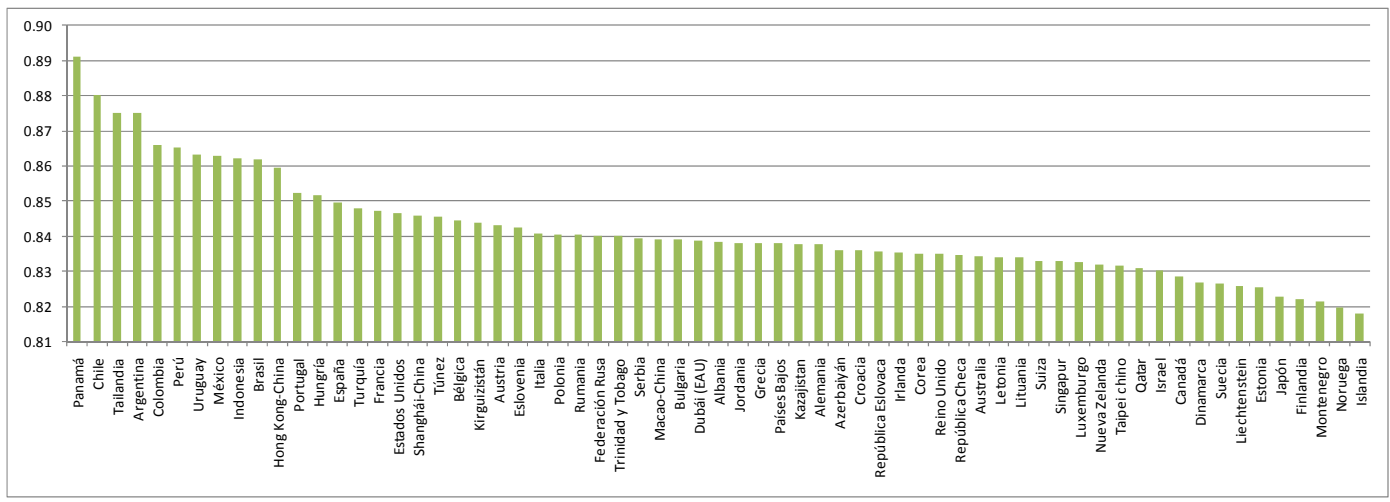

Fuente: Elaboración propia en base a PISA 2009.

Gráfico A2.3. Niveles de segregación escolar por nivel socioeconómico. Año 2009. Índice de la Raíz Cuadrada (nivel socioeconómico bajo: 4 quintiles más bajos de ESCS).

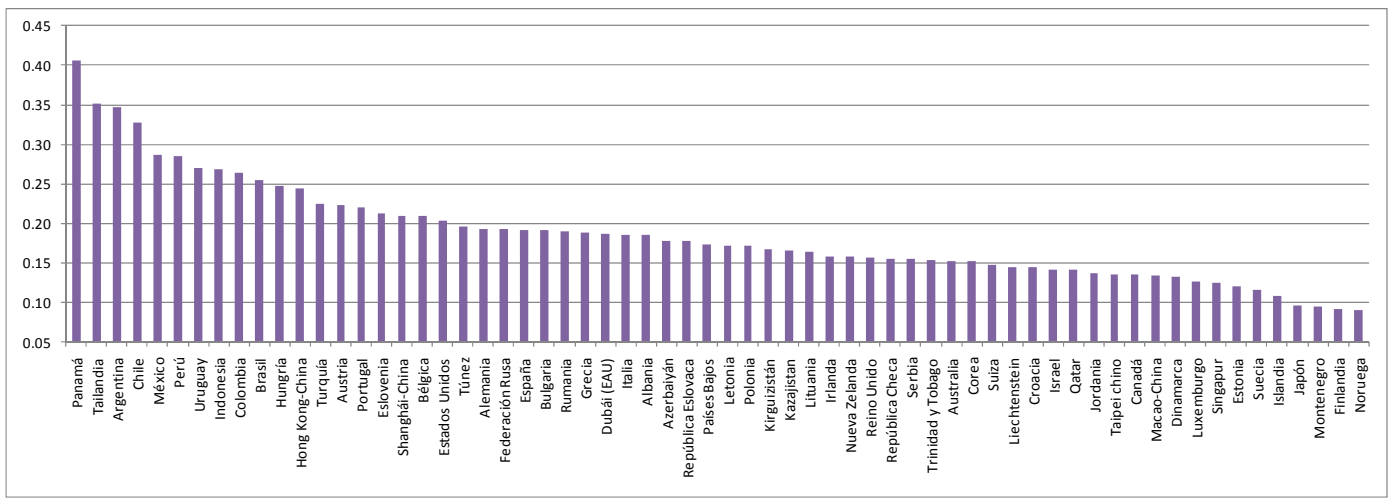

Fuente: Elaboración propia en base a PISA 2009. 
Gráfico A3.1. Cambio en la segregación escolar por nivel socioeconómico entre 2000 y 2009. Índice de Disimilitud (nivel socioeconómico bajo: 1er quintil de ESCS).

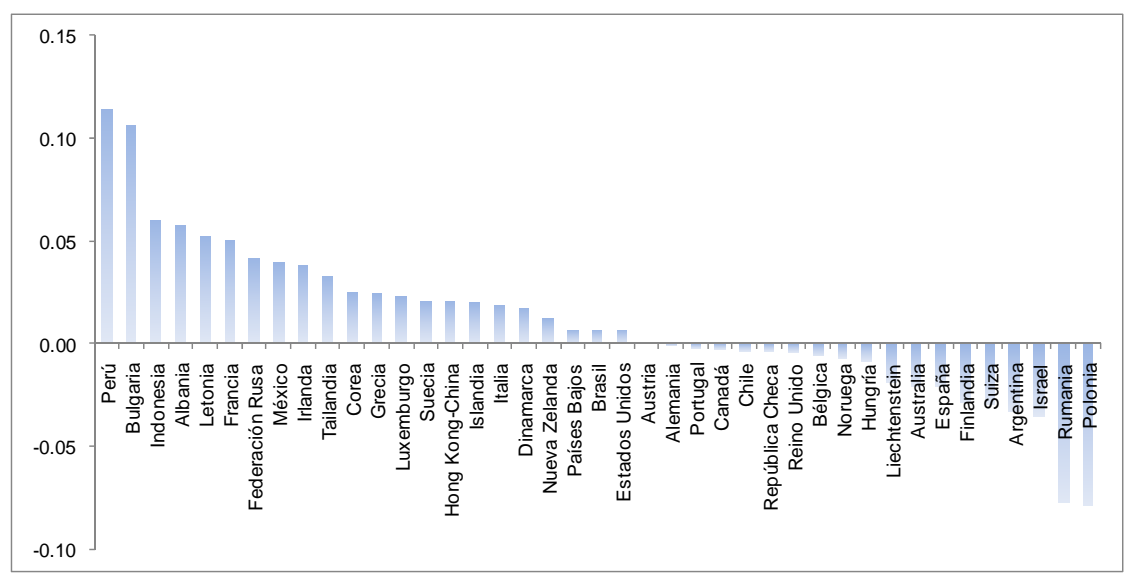

Gráfico A3.2. Cambio en la segregación escolar por nivel socioeconómico entre 2000 y 2009. Índice de Aislamiento (nivel socioeconómico bajo: 1er quintil de ESCS).

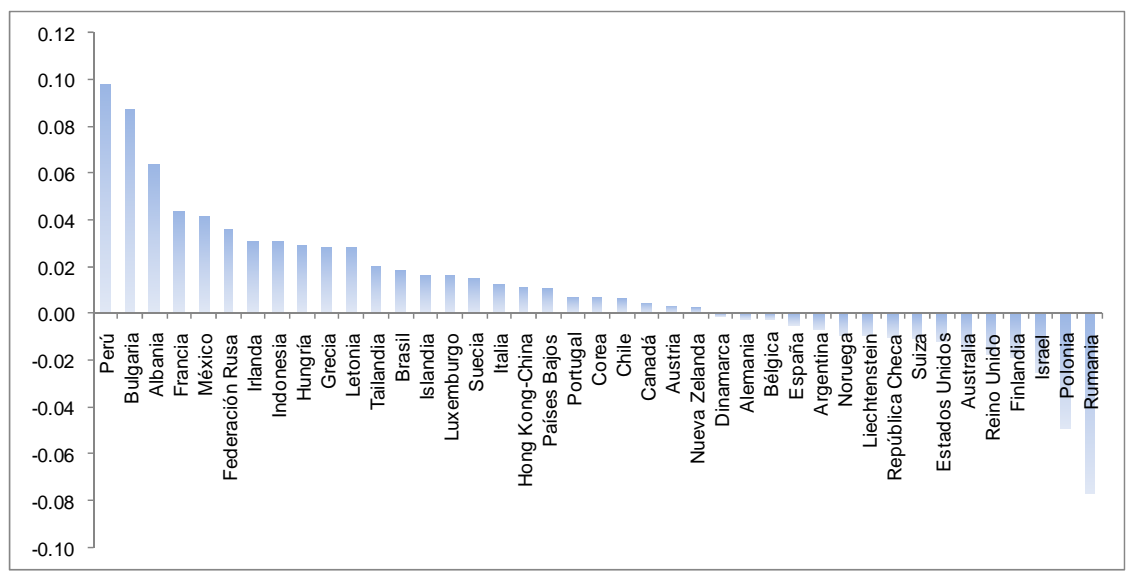

Gráfico A3.3. Cambio en la segregación escolar por nivel socioeconómico entre 2000 y 2009. Índice de la Raíz Cuadrada (nivel socioeconómico bajo: 1er quintil de ESCS).

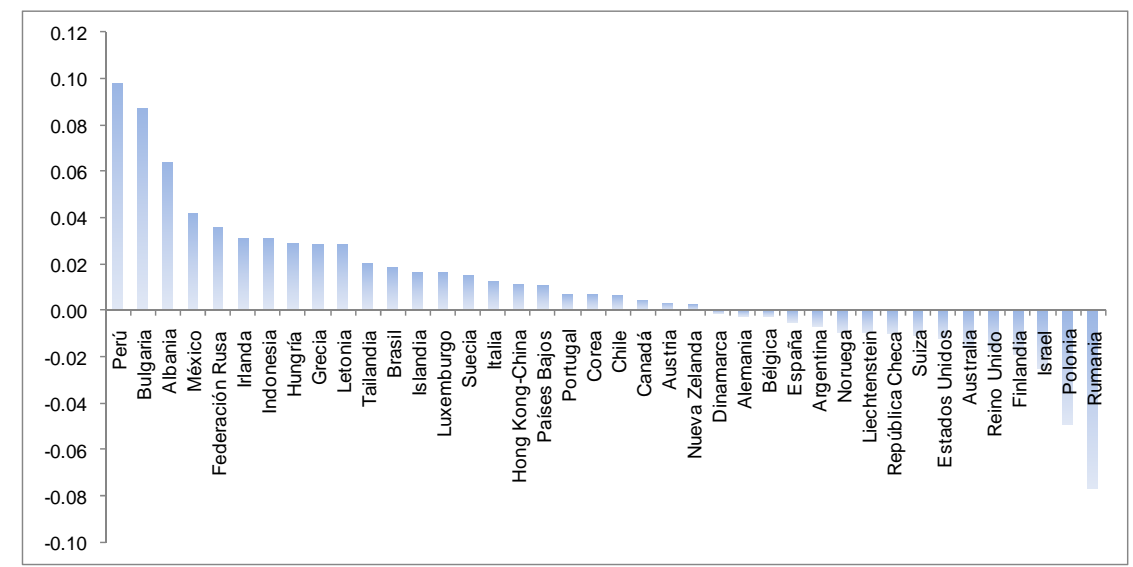


Gráfico A4.1. Cambio en la segregación escolar por nivel socioeconómico entre 2000 y 2009. Índice de Disimilitud (nivel socioeconómico bajo: 4 quintiles más bajos de ESCS).

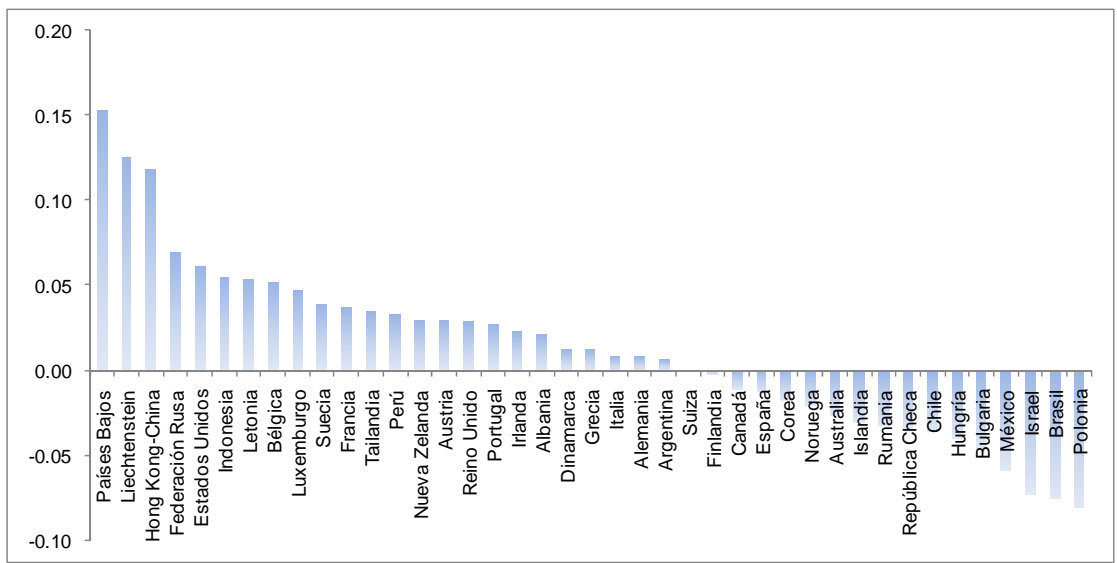

Gráfico A4.2. Cambio en la segregación escolar por nivel socioeconómico entre 2000 y 2009. Índice de Aislamiento (nivel socioeconómico bajo: 4 quintiles más bajos de ESCS).

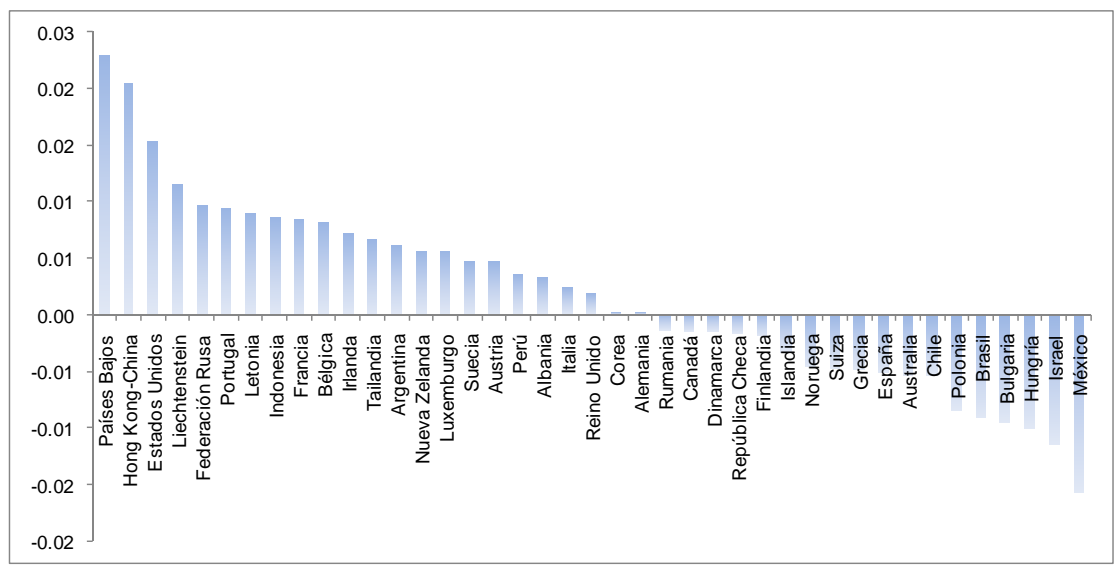

Gráfico A4.3. Cambio en la segregación escolar por nivel socioeconómico entre 2000 y 2009. Índice de la Raíz Cuadrada (nivel socioeconómico bajo: 4 quintiles más bajos de ESCS).

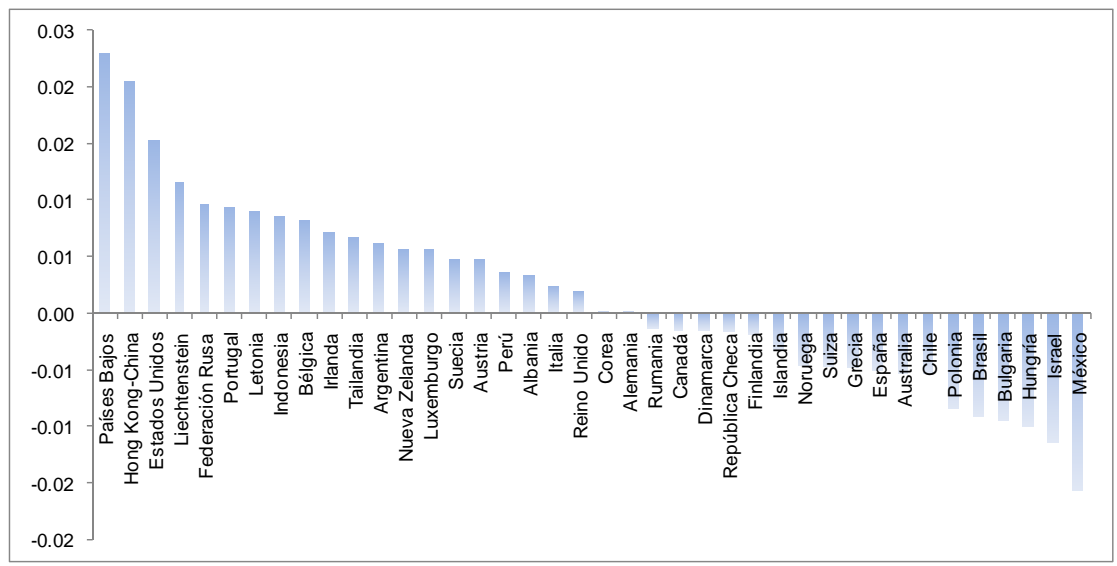


Cuadro A1.1. Regresiones de segregación escolar por nivel socioeconómico. Variable dependiente: D (nivel socioeconómico bajo: 1er quintil de ESCS).

\begin{tabular}{|c|c|c|c|c|c|c|}
\hline \multirow{2}{*}{ Variables explicativas } & \multicolumn{6}{|c|}{ Estimaciones por Efectos Fijos } \\
\hline & (1) & $(2)$ & $(3)$ & (4) & $(5)$ & (6) \\
\hline Desigualdad (varianza del ESCS) & $\begin{array}{l}0.131^{\star \star \star} \\
(0.0209)\end{array}$ & $\begin{array}{l}0.125^{\star \star \star} \\
(0.0213)\end{array}$ & $\begin{array}{l}0.121^{\star \star \star} \\
(0.0187)\end{array}$ & $\begin{array}{l}0.125^{\star \star \star} \\
(0.0199)\end{array}$ & $\begin{array}{l}0.122^{\star \star \star} \\
(0.0201)\end{array}$ & $\begin{array}{l}0.124^{\star \star \star} \\
(0.0199)\end{array}$ \\
\hline Nivel socioeconómico (ESCS) promedio & & $\begin{array}{l}-0.0160 \\
(0.0224)\end{array}$ & $\begin{array}{l}-0.0287 \\
(0.0234)\end{array}$ & $\begin{array}{l}-0.0180 \\
(0.0212)\end{array}$ & $\begin{array}{l}-0.0248 \\
(0.0230)\end{array}$ & $\begin{array}{l}-0.0369 \\
(0.0242)\end{array}$ \\
\hline Proporción de estudiantes en escuelas rurales & & & $\begin{array}{l}-0.113^{\star \star} \\
(0.0547)\end{array}$ & $\begin{array}{l}-0.116^{\star \star} \\
(0.0553)\end{array}$ & $\begin{array}{l}-0.103^{\star \star} \\
(0.0466)\end{array}$ & $\begin{array}{l}-0.120^{\star \star \star \star} \\
(0.0451)\end{array}$ \\
\hline Proporción de estudiantes en escuelas privadas & & & & $\begin{array}{l}-0.00626 \\
(0.0142)\end{array}$ & $\begin{array}{l}-0.00543 \\
(0.0139)\end{array}$ & $\begin{array}{l}-0.00827 \\
(0.0155)\end{array}$ \\
\hline Tasa de asistencia bruta a la secundaria & & & & & $\begin{array}{l}-0.00501 \\
(0.0341)\end{array}$ & $\begin{array}{l}-0.00824 \\
(0.0313)\end{array}$ \\
\hline Año 2000 & & & & & & $\begin{array}{l}-0.00121 \\
(0.00474)\end{array}$ \\
\hline Año 2003 & & & & & & $\begin{array}{l}0.0117^{\star *} \\
(0.00584)\end{array}$ \\
\hline Año 2006 & & & & & & $\begin{array}{c}0.00601 \\
(0.00397)\end{array}$ \\
\hline Constante & $\begin{array}{l}0.289^{\star \star \star} \\
(0.0189)\end{array}$ & $\begin{array}{l}0.291^{\star \star \star} \\
(0.0184)\end{array}$ & $\begin{array}{l}0.305^{\star \star \star} \\
(0.0187)\end{array}$ & $\begin{array}{l}0.305^{\star \star \star} \\
(0.0182)\end{array}$ & $\begin{array}{l}0.309^{\star \star \star} \\
(0.0371)\end{array}$ & $\begin{array}{l}0.307^{\star \star \star} \\
(0.0324)\end{array}$ \\
\hline Observaciones & 204 & 204 & 195 & 190 & 183 & 183 \\
\hline R cuadrado & 0.254 & 0.256 & 0.286 & 0.277 & 0.284 & 0.335 \\
\hline Número de Países & 66 & 66 & 66 & 66 & 64 & 64 \\
\hline
\end{tabular}

Cuadro A1.2. Regresiones de segregación escolar por nivel socioeconómico. Variable dependiente: A (nivel socioeconómico bajo: 1er quintil de ESCS).

\begin{tabular}{|c|c|c|c|c|c|c|}
\hline \multirow{2}{*}{ Variables explicativas } & \multicolumn{6}{|c|}{ Estimaciones por Efectos Fijos } \\
\hline & (1) & (2) & (3) & (4) & (5) & (6) \\
\hline Desigualdad (varianza del ESCS) & $\begin{array}{l}0.103^{\star \star \star} \\
(0.0185)\end{array}$ & $\begin{array}{c}0.0998^{\star \star \star} \\
(0.0178)\end{array}$ & $\begin{array}{c}0.0954^{\star \star \star} \\
(0.0154)\end{array}$ & $\begin{array}{c}0.0974^{\star \star \star} \\
(0.0160)\end{array}$ & $\begin{array}{c}0.0951^{\star \star \star} \\
(0.0156)\end{array}$ & $\begin{array}{c}0.0953^{\star \star \star} \\
(0.0160)\end{array}$ \\
\hline Nivel socioeconómico (ESCS) promedio & & $\begin{array}{l}-0.00872 \\
(0.0204)\end{array}$ & $\begin{array}{l}-0.0169 \\
(0.0214)\end{array}$ & $\begin{array}{l}-0.00625 \\
(0.0190)\end{array}$ & $\begin{array}{l}-0.0130 \\
(0.0204)\end{array}$ & $\begin{array}{c}-0.0227 \\
(0.0214)\end{array}$ \\
\hline Proporción de estudiantes en escuelas rurales & & & $\begin{array}{l}-0.0680 \\
(0.0442)\end{array}$ & $\begin{array}{l}-0.0701 \\
(0.0445)\end{array}$ & $\begin{array}{l}-0.0561 \\
(0.0378)\end{array}$ & $\begin{array}{l}-0.0702^{*} \\
(0.0378)\end{array}$ \\
\hline Proporción de estudiantes en escuelas privadas & & & & $\begin{array}{l}-0.00160 \\
(0.0177)\end{array}$ & $\begin{array}{c}-0.00135 \\
(0.0169)\end{array}$ & $\begin{array}{c}-0.00302 \\
(0.0177)\end{array}$ \\
\hline Tasa de asistencia bruta a la secundaria & & & & & $\begin{array}{c}-0.0104 \\
(0.0273)\end{array}$ & $\begin{array}{l}-0.00925 \\
(0.0255)\end{array}$ \\
\hline Año 2000 & & & & & & $\begin{array}{l}-0.00152 \\
(0.00381)\end{array}$ \\
\hline Año 2003 & & & & & & $\begin{array}{l}0.00682^{*} \\
(0.00397)\end{array}$ \\
\hline Año 2006 & & & & & & $\begin{array}{l}0.00636^{\star \star} \\
(0.00295)\end{array}$ \\
\hline Constante & $\begin{array}{l}0.242^{\star \star \star} \\
(0.0167)\end{array}$ & $\begin{array}{l}0.243^{\star \star \star} \\
(0.0159)\end{array}$ & $\begin{array}{l}0.253^{\star \star \star} \\
(0.0158)\end{array}$ & $\begin{array}{l}0.254^{\star \star \star} \\
(0.0151)\end{array}$ & $\begin{array}{l}0.264^{\star \star \star} \\
(0.0293)\end{array}$ & $\begin{array}{l}0.259^{\star \star \star} \\
(0.0263)\end{array}$ \\
\hline Observaciones & 204 & 204 & 195 & 190 & 183 & 183 \\
\hline R cuadrado & 0.273 & 0.274 & 0.287 & 0.282 & 0.289 & 0.343 \\
\hline Número de Países & 66 & 66 & 66 & 66 & 64 & 64 \\
\hline
\end{tabular}

Cuadro A1.3. Regresiones de segregación escolar por nivel socioeconómico. Variable dependiente: H (nivel socioeconómico bajo: 1er quintil de ESCS).

\begin{tabular}{|c|c|c|c|c|c|c|}
\hline \multirow{2}{*}{ Variables explicativas } & \multicolumn{6}{|c|}{ Estimaciones por Efectos Fijos } \\
\hline & (1) & (2) & (3) & (4) & (5) & (6) \\
\hline Desigualdad (varianza del ESCS) & $\begin{array}{l}0.124^{\star \star \star} \\
(0.0389)\end{array}$ & $\begin{array}{l}0.137^{\star \star *} \\
(0.0434)\end{array}$ & $\begin{array}{l}0.143^{\star \star \star} \\
(0.0466)\end{array}$ & $\begin{array}{l}0.108^{\star \star \star} \\
(0.0161)\end{array}$ & $\begin{array}{l}0.104^{\star \star \star} \\
(0.0154)\end{array}$ & $\begin{array}{l}0.108^{\star \star \star} \\
(0.0167)\end{array}$ \\
\hline Nivel socioeconómico (ESCS) promedio & & $\begin{array}{c}0.0320 \\
(0.0366)\end{array}$ & $\begin{array}{c}0.0509 \\
(0.0354)\end{array}$ & $\begin{array}{l}0.00373 \\
(0.0189)\end{array}$ & $\begin{array}{l}-0.00557 \\
(0.0198)\end{array}$ & $\begin{array}{l}-0.0108 \\
(0.0217)\end{array}$ \\
\hline Proporción de estudiantes en escuelas rurales & & & $\begin{array}{l}-0.0810 \\
(0.0516)\end{array}$ & $\begin{array}{c}-0.0751 \\
(0.0465)\end{array}$ & $\begin{array}{l}-0.0553 \\
(0.0402)\end{array}$ & $\begin{array}{l}-0.0665 \\
(0.0405)\end{array}$ \\
\hline Proporción de estudiantes en escuelas privadas & & & & $\begin{array}{c}0.0133 \\
(0.0178)\end{array}$ & $\begin{array}{c}0.0139 \\
(0.0168)\end{array}$ & $\begin{array}{c}0.0137 \\
(0.0172)\end{array}$ \\
\hline Tasa de asistencia bruta a la secundaria & & & & & $\begin{array}{l}-0.0119 \\
(0.0246)\end{array}$ & $\begin{array}{l}-0.0131 \\
(0.0233)\end{array}$ \\
\hline Año 2000 & & & & & & $\begin{array}{c}0.00165 \\
(0.00428)\end{array}$ \\
\hline Año 2003 & & & & & & $\begin{array}{c}0.00774 \\
(0.00474)\end{array}$ \\
\hline Año 2006 & & & & & & $\begin{array}{c}0.00516 \\
(0.00331)\end{array}$ \\
\hline Constante & $\begin{array}{c}0.0469 \\
(0.0351)\end{array}$ & $\begin{array}{c}0.0424 \\
(0.0357)\end{array}$ & $\begin{array}{c}0.0530 \\
(0.0399)\end{array}$ & $\begin{array}{c}0.0763^{\star \star \star} \\
(0.0147)\end{array}$ & $\begin{array}{c}0.0875^{\star \star \star} \\
(0.0266)\end{array}$ & $\begin{array}{c}0.0818^{\star \star \star} \\
(0.0241)\end{array}$ \\
\hline Observaciones & 204 & 204 & 195 & 190 & 183 & 183 \\
\hline$R$ cuadrado & 0.129 & 0.135 & 0.172 & 0.268 & 0.274 & 0.304 \\
\hline Número de Países & 66 & 66 & 66 & 66 & 64 & 64 \\
\hline
\end{tabular}


Cuadro A2.1. Regresiones de segregación escolar por nivel socioeconómico. Variable dependiente: D(nivel socioeconómico bajo: 4 primeros quintiles de ESCS)

\begin{tabular}{|c|c|c|c|c|c|c|}
\hline \multirow{2}{*}{ Variables explicativas } & \multicolumn{6}{|c|}{ Estimaciones por Efectos Fijos } \\
\hline & (1) & (2) & (3) & (4) & (5) & (6) \\
\hline Desigualdad (varianza del ESCS) & $\begin{array}{c}0.0789^{\star \star \star} \\
(0.0256)\end{array}$ & $\begin{array}{c}0.0991^{* * \star} \\
(0.0278)\end{array}$ & $\begin{array}{l}0.108^{\star \star *} \\
(0.0327)\end{array}$ & $\begin{array}{c}0.0965^{\star * *} \\
(0.0356)\end{array}$ & $\begin{array}{c}0.0978^{\star \star \star \star} \\
(0.0354)\end{array}$ & $\begin{array}{l}0.104^{\star \star \star} \\
(0.0332)\end{array}$ \\
\hline Nivel socioeconómico (ESCS) promedio & & 0.0520 & 0.0400 & 0.0460 & 0.0411 & 0.0329 \\
\hline & & $(0.0312)$ & $(0.0312)$ & $(0.0314)$ & $(0.0351)$ & $(0.0386)$ \\
\hline Proporción de estudiantes en escuelas rurales & & & $-0.192^{\star \star}$ & $-0.184^{*}$ & -0.132 & $-0.147^{*}$ \\
\hline & & & $(0.0919)$ & $(0.0936)$ & $(0.0809)$ & $(0.0769)$ \\
\hline Proporción de estudiantes en escuelas privadas & & & & $\begin{array}{l}0.0953^{\star * *} \\
(0.0244)\end{array}$ & $\begin{array}{l}0.0901^{\star \star \star *} \\
(0.0250)\end{array}$ & $\begin{array}{c}0.0883^{\star \star *} \\
(0.0283)\end{array}$ \\
\hline Tasa de asistencia bruta a la secundaria & & & & & $\begin{array}{l}-0.0554^{* *} \\
(0.0229)\end{array}$ & $\begin{array}{c}-0.0621^{\star \star \star} \\
(0.0232)\end{array}$ \\
\hline Año 2000 & & & & & & $\begin{array}{c}0.00182 \\
(0.00844)\end{array}$ \\
\hline Año 2003 & & & & & & $\begin{array}{c}0.0134^{\star} \\
(0.00733)\end{array}$ \\
\hline Año 2006 & & & & & & $\begin{array}{c}0.00449 \\
(0.00471)\end{array}$ \\
\hline Constante & $\begin{array}{l}0.363^{\star * \star} \\
(0.0231)\end{array}$ & $\begin{array}{l}0.356^{\star \star \star} \\
(0.0234)\end{array}$ & $\begin{array}{l}0.367^{\star \star \star} \\
(0.0271)\end{array}$ & $\begin{array}{l}0.360^{* * \star} \\
(0.0282)\end{array}$ & $\begin{array}{l}0.409^{\star \star \star} \\
(0.0289)\end{array}$ & $\begin{array}{l}0.406^{\star \star \star} \\
(0.0269)\end{array}$ \\
\hline Observaciones & 204 & 204 & 195 & 190 & 183 & 183 \\
\hline R cuadrado & 0.055 & 0.070 & 0.130 & 0.165 & 0.163 & 0.193 \\
\hline Número de Países & 66 & 66 & 66 & 66 & 64 & 64 \\
\hline
\end{tabular}

Cuadro A2.2. Regresiones de segregación escolar por nivel socioeconómico. Variable dependiente: A(nivel socioeconómico bajo: 4 primeros quintiles de ESCS)

\begin{tabular}{|c|c|c|c|c|c|c|}
\hline \multirow{2}{*}{ Variables explicativas } & \multicolumn{6}{|c|}{ Estimaciones por Efectos Fijos } \\
\hline & (1) & (2) & (3) & (4) & (5) & (6) \\
\hline Desigualdad (varianza del ESCS) & $\begin{array}{l}0.0150^{\star \star \star} \\
(0.00519)\end{array}$ & $\begin{array}{l}0.0175^{\star \star \star} \\
(0.00528)\end{array}$ & $\begin{array}{l}0.0190^{\star \star \star} \\
(0.00554)\end{array}$ & $\begin{array}{l}0.0174^{\star \star \star} \\
(0.00610)\end{array}$ & $\begin{array}{l}0.0181^{\star \star \star} \\
(0.00642)\end{array}$ & $\begin{array}{l}0.0190^{\star \star \star} \\
(0.00602)\end{array}$ \\
\hline Nivel socioeconómico (ESCS) promedio & & $\begin{array}{c}0.00619 \\
(0.00564)\end{array}$ & $\begin{array}{c}0.00411 \\
(0.00598)\end{array}$ & $\begin{array}{c}0.00520 \\
(0.00617)\end{array}$ & $\begin{array}{c}0.00578 \\
(0.00692)\end{array}$ & $\begin{array}{c}0.00461 \\
(0.00720)\end{array}$ \\
\hline Proporción de estudiantes en escuelas rurales & & & $\begin{array}{c}-0.0296^{\star \star} \\
(0.0139)\end{array}$ & $\begin{array}{l}-0.0283^{*} \\
(0.0143)\end{array}$ & $\begin{array}{l}-0.0232^{\star} \\
(0.0131)\end{array}$ & $\begin{array}{c}-0.0258^{\star *} \\
(0.0123)\end{array}$ \\
\hline Proporción de estudiantes en escuelas privadas & & & & $\begin{array}{l}0.0164^{* \star *} \\
(0.00384)\end{array}$ & $\begin{array}{l}0.0156^{\star \star \star} \\
(0.00399)\end{array}$ & $\begin{array}{l}0.0156^{\star \star *} \\
(0.00451)\end{array}$ \\
\hline Tasa de asistencia bruta a la secundaria & & & & & $\begin{array}{l}-0.00686 \\
(0.00458)\end{array}$ & $\begin{array}{l}-0.00705 \\
(0.00465)\end{array}$ \\
\hline Año 2000 & & & & & & $\begin{array}{l}0.000395 \\
(0.00143)\end{array}$ \\
\hline Año 2003 & & & & & & $\begin{array}{c}0.00172 \\
(0.00133)\end{array}$ \\
\hline Año 2006 & & & & & & $\begin{array}{c}0.00124 \\
(0.000868)\end{array}$ \\
\hline Constante & $\begin{array}{c}0.828^{\star \star \star} \\
(0.00468)\end{array}$ & $\begin{array}{c}0.827^{\star \star \star} \\
(0.00458)\end{array}$ & $\begin{array}{l}0.828^{\star \star \star} \\
(0.00498)\end{array}$ & $\begin{array}{c}0.827^{\star \star \star} \\
(0.00526)\end{array}$ & $\begin{array}{c}0.833^{\star \star \star} \\
(0.00555)\end{array}$ & $\begin{array}{l}0.832^{\star \star \star} \\
(0.00524)\end{array}$ \\
\hline Observaciones & 204 & 204 & 195 & 190 & 183 & 183 \\
\hline$R$ cuadrado & 0.066 & 0.073 & 0.123 & 0.158 & 0.154 & 0.172 \\
\hline Número de Países & 66 & 66 & 66 & 66 & 64 & 64 \\
\hline
\end{tabular}

Cuadro A2.3. Regresiones de segregación escolar por nivel socioeconómico. Variable dependiente: H(nivel socioeconómico bajo: 4 primeros quintiles de ESCS)

\begin{tabular}{|c|c|c|c|c|c|c|}
\hline \multirow{2}{*}{ Variables explicativas } & \multicolumn{6}{|c|}{ Estimaciones por Efectos Fijos } \\
\hline & (1) & (2) & (3) & (4) & (5) & (6) \\
\hline Desigualdad (varianza del ESCS) & $\begin{array}{c}0.103^{\star \star} \\
(0.0497)\end{array}$ & $\begin{array}{c}0.122^{\star \star} \\
(0.0562)\end{array}$ & $\begin{array}{c}0.146^{\star \star} \\
(0.0626)\end{array}$ & $\begin{array}{c}0.0974^{\star \star \star} \\
(0.0278)\end{array}$ & $\begin{array}{c}0.0943^{\star \star \star} \\
(0.0283)\end{array}$ & $\begin{array}{l}0.102^{\star \star \star} \\
(0.0265)\end{array}$ \\
\hline Nivel socioeconómico (ESCS) promedio & & $\begin{array}{c}0.0479 \\
(0.0503)\end{array}$ & $\begin{array}{c}0.0647 \\
(0.0518)\end{array}$ & $\begin{array}{c}0.0129 \\
(0.0263)\end{array}$ & $\begin{array}{l}0.00531 \\
(0.0305)\end{array}$ & $\begin{array}{c}0.000624 \\
(0.0316)\end{array}$ \\
\hline Proporción de estudiantes en escuelas rurales & & & $\begin{array}{l}-0.169^{\star *} \\
(0.0640)\end{array}$ & $\begin{array}{c}-0.160^{* * *} \\
(0.0597)\end{array}$ & $\begin{array}{l}-0.132^{\star *} \\
(0.0593)\end{array}$ & $\begin{array}{c}-0.144^{\star \star \star} \\
(0.0537)\end{array}$ \\
\hline Proporción de estudiantes en escuelas privadas & & & & $\begin{array}{c}0.0651^{\star \star \star} \\
(0.0188)\end{array}$ & $\begin{array}{c}0.0640^{\star \star \star} \\
(0.0195)\end{array}$ & $\begin{array}{c}0.0641^{\star \star \star} \\
(0.0224)\end{array}$ \\
\hline Tasa de asistencia bruta a la secundaria & & & & & $\begin{array}{c}-0.0192 \\
(0.0202)\end{array}$ & $\begin{array}{l}-0.0236 \\
(0.0219)\end{array}$ \\
\hline Año 2000 & & & & & & $\begin{array}{c}0.00374 \\
(0.00674)\end{array}$ \\
\hline Año 2003 & & & & & & $\begin{array}{c}0.0114^{*} \\
(0.00577)\end{array}$ \\
\hline Año 2006 & & & & & & $\begin{array}{c}0.00533 \\
(0.00436)\end{array}$ \\
\hline Constante & $\begin{array}{c}0.0833^{\star} \\
(0.0449)\end{array}$ & $\begin{array}{l}0.0766^{*} \\
(0.0456)\end{array}$ & $\begin{array}{c}0.0812 \\
(0.0529)\end{array}$ & $\begin{array}{l}0.107^{\star \star \star} \\
(0.0216)\end{array}$ & $\begin{array}{l}0.125^{\star \star \star} \\
(0.0226)\end{array}$ & $\begin{array}{l}0.118^{\star \star \star} \\
(0.0232)\end{array}$ \\
\hline Observaciones & 204 & 204 & 195 & 190 & 183 & 183 \\
\hline R cuadrado & 0.066 & 0.075 & 0.152 & 0.196 & 0.183 & 0.211 \\
\hline Número de Países & 66 & 66 & 66 & 66 & 64 & 64 \\
\hline
\end{tabular}

